\title{
Recent Trends in Precipitation Over the Myanmar Coast During Onset and Withdrawal Phases of Monsoon Season
}

\author{
Xiao Yan (D 576294397@qq.com ) \\ Wuhan University https://orcid.org/0000-0002-9157-1866 \\ Yibin Yao \\ Wuhan University \\ Yuanjian Yang \\ Nanjing University of Information Science \& Technology \\ Liang Zhang \\ Wuhan University \\ Bao Zhang \\ Wuhan University
}

\section{Research Article}

Keywords: Precipitation, Monsoon Season, Myanmar Coast

Posted Date: March 19th, 2021

DOI: https://doi.org/10.21203/rs.3.rs-325462/v1

License: (9) This work is licensed under a Creative Commons Attribution 4.0 International License. Read Full License 
1 Recent trends in precipitation over the Myanmar Coast 2 during onset and withdrawal phases of monsoon season

3 Xiao Yan ${ }^{1}$, Yibin Yao*1, Yuanjian Yang ${ }^{2}$, Liang Zhang ${ }^{* 1}$, Bao Zhang ${ }^{1}$

$4{ }^{1}$ School of Geodesy and Geomatics, Wuhan University, Wuhan 430079, China

2 School of Atmospheric Physics, Nanjing University of Information Science \& 6 Technology, Nanjing, China

7 Correspondence to Yibin Yao (ybyao@whu.edu.cn), Liang Zhang (qgzhliang@w 8 hu.edu.cn)

Abstract: Monsoon precipitation is the major driver of agricultural productivity in the Myanmar Coast, it is crucial to quantify and understand recent changes in precipitation during the monsoon season over this region. By using multiple precipitation datasets, we demonstrate that total precipitation during monsoon season over the Myanmar Coast has increased slightly but not significantly, but precipitation during the onset and withdrawal phases of monsoon season exhibit a significant increasing trend during 1979-2015, and the contribution of precipitation during the two phases to total monsoon precipitation has increased significantly. The increased precipitation during the onset phase over the Myanmar Coast directly results from the earlier onset of the South Asian Summer Monsoon in recent decades, which is associated with the phase transition of the Inter-decadal Pacific Oscillation in the late 1990s. And the precipitation increase during the withdrawal phase is directly due to the enhances of the ascending motion and convection around this region, which is dynamically correlated to the anomalous cyclone-like circulation around the Bay of Bengal as well as the strengthening of the cross-equatorial flow around the equatorial Indian Ocean.

\section{Declarations}

Funding: This work was supported by the National Natural Science Foundation of China [grant numbers 41704004, 42074035] and the Fundamental Research Funds for the Central Universities [2042020kf0009] and the China Postdoctoral Science Foundation (2018M630880; 2019T120687). or personal relationships that could have appeared to influence the work reported in this paper.

\section{Acknowledgments}

The GPCP precipitation and ERSSTv5 data are provided by NOAA/OAR/ESRL PSL from their website at https://psl.noaa.gov/. The GPCC precipitation data is obtained from http://g pcc.dwd.de/. The APHRODITE precipitation data is obtained from http://aphrodite.st.hirosak i-u.ac.jp/download/. The ERA-Interim data is provided by ECMWF from their website at $\mathrm{h}$ ttp://apps.ecmwf.int/datasets/. The Outgoing Longwave Radiation data are provided by NOA A's National Centers for Environmental Information from their website at https://www.ncei. noaa.gov/.

\section{Introduction}

Monsoon precipitation is the major driver of agricultural productivity in many tropical and 
subtropical regions in the world, and its variability influences the livelihood of a large share of the world's population (Parthasarathy et al. 1994). Recent changes of monsoon and monsoon precipitation have been intensively examined on the global scale (Pang-chi and Hsu 2011; Wang et al. 2012) and regional scales, e.g., South Asia (Bollasina et al. 2011; Turner and Annamalai 2012; Misra and DiNapoli 2014; Shahi et al. 2018), and East Asia (Chan and Zhou 2005; Kajikawa and Wang 2012; Lu et al. 2016; Huang et al. 2018). These studies are conducted on large scales and provide valuable results and conclusions. However, each regional monsoon and monsoon precipitation exhibit indigenous variation patterns due to the heterogeneity of topography, land-ocean distributions, and internal feedback processes in the climate system of different regions (Wang et al. 2012). Monsoon and monsoon precipitation in small scales, especially in some typical areas, are worthy of specific study to capture more spatial details.

One characteristic feature of monsoon precipitation in Monsoon Asia is the coastally oriented narrow precipitation maxima along the Myanmar coast, which is the result of the interaction between the northward propagating monsoon intraseasonal oscillation and the shallow orography (Romatschke and Houze 2011; Kumar et al. 2014; Shige et al. 2017). And the monsoon precipitation over the Myanmar Coast represents an important heat source in the tropical climate system, which plays a seminal role in the variation of the tropospheric temperature gradient between ocean and land and Asian monsoon circulation (Kumar et al. 2014). The earliest onset of the South Asian Summer Monsoon (SASM) typically occurs in the Bay of Bengal (BOB) and Myanmar Coast, i.e. the latter is the land that first experiences the summer monsoon and monsoon precipitation (Wang 2002; Fosu and Wang 2015). Given its particularity in the monsoon system, the Myanmar Coast is very sensitive to the SASM changes, which are well reflected in monsoon precipitation over this region. Consequently, the monsoon precipitation changes over the Myanmar Coast can serve as an important indicator of the SASM changes. Studying precipitation changes in the Myanmar Coast related to the SASM can also provide valuable information for understanding precipitation variability in downstream SASM regions, e.g., Southwest China (Takahashi and Yasunari 2006). Therefore, we believe Myanmar Coast provides an appropriate test bed for studying the summer monsoon and monsoon precipitation and thus choose this region as the research area.

Myanmar Coast concerned in this study is located in the northwestern part of the Indochina Peninsula and the northeast bank of the BOB (Fig. 1). It is one major grain-producing region in Myanmar and even in the world with a third of the country's population, thanks to abundant precipitation here. Since this region's economy depends heavily on rain-fed agriculture and related industries (Sein and Zhi 2016), the precipitation change here is closely related to local people's livelihood and socioeconomic and remains an important scientific issue (Kumar et al. 2014; Shige et al. 2017).

The climate system in Myanmar Coast is predominated by the SASM. According to the Asia-Pacific monsoon division by Wang (2002), Myanmar Coast is located in the Indian monsoon subsystem. This region experiences three different weather seasons in the year: the winter or dry and cool season from November to February, the summer or hot season from March to April, and the rainy or southwest monsoon season from May to October (Lwin 2000; Aung et al. 2017; Chhin et al. 2020). Climatologically, precipitation in the monsoon season accounts for $95 \%$ of total precipitation while the remaining $5 \%$ occurs in the other half year. Monsoon precipitation plays an important role in agricultural productivity in this region, and its change under global 
warming imposes a great social and economic impact on this region's population (Gadgil and Sulochana 2004; Pang-chi and Hsu 2011). Quantifying and understanding recent changes of monsoon precipitation over this region is important to predict its future and reflect its past (Wang et al. 2012).

Monsoon in the Myanmar Coast can be reviewed systematically because of its specific land-ocean configuration and shallow orography (Wang 2002; Kumar et al. 2014), and its variations call for specific studies. Interannual variations of monsoon precipitation in this region have been investigated in several studies (Sen Roy and Sen Roy 2011; Sein and Zhi 2016; Shrivastava et al. 2017). However, most of these studies used a single precipitation dataset, which may give unreliable results due to data quality deficiency over this region where in-situ observations are sparse (Ghosh et al. 2009; Wang et al. 2011; Wang et al. 2013). And recent trends of monsoon precipitation over the Myanmar Coast have not been studied. This motivates us to conduct a comprehensive investigation into recent trends of monsoon precipitation over the Myanmar Coast using multiple precipitation data sets.

Through this study, we expect to (1) robustly quantify recent $\sim 40$-year trends of the monsoon precipitation over the Myanmar Coast using different precipitation data sets and (2) understand mechanisms for the trends in the monsoon precipitation.

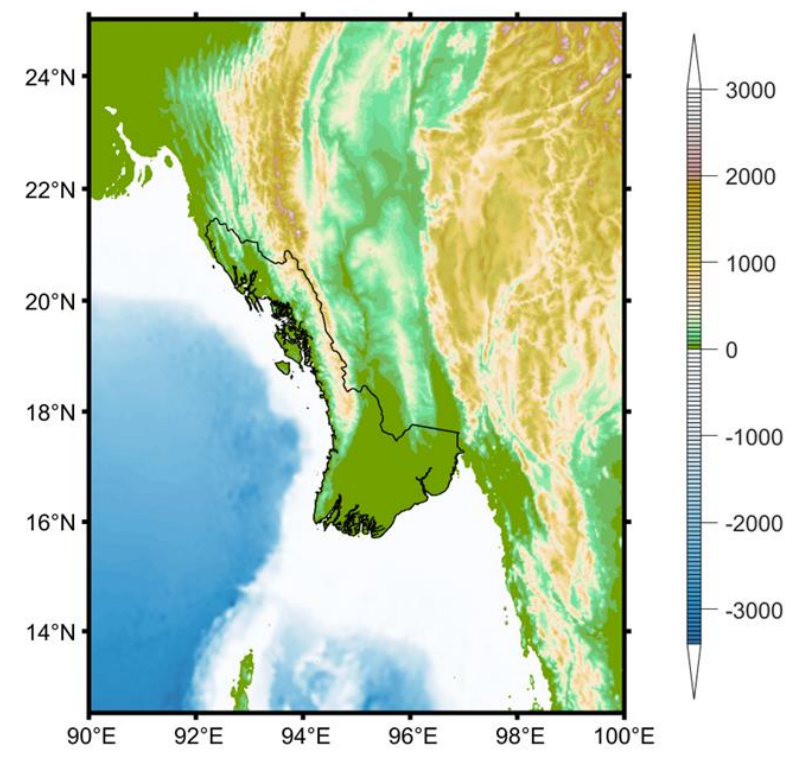

Fig. 1. The topography of Myanmar Coast

\section{Data and Method}

\subsection{Data}

Precipitation and other meteorological data used in this study include the following.

1. Monthly precipitation from Global Precipitation Climatology Project (GPCP) version 2 (Adler et al. 2003; Huffman et al. 2009), Global Precipitation Climatology Center (GPCC) (http://gpcc.dwd.de/), and Asian Precipitation-Highly Resolved Observational Data Integration towards Evaluation (APHRODITE) (Yatagai et al. 2012) are collected for precipitation trend analysis. All of these are gridded precipitation datasets that cover the majority of the globe completely, and again the spatial resolution and time span for each of these precipitation datasets are provided in Table 1. In this study, these different datasets are used together to identify and quantify precipitation trends since a single dataset may give spurious trends related to changing 
observation systems (Paltridge et al. 2009).

2. Daily precipitation from APHRODITE is used to count precipitation amount, days, and intensity in the specified period.

3. Pentad precipitation from GPCP is used to determine the local onset date of the summer monsoon.

4. European Centre for Medium-Range Weather Forecasts Interim Reanalysis (ERA-Interim), one of the most recent reanalysis datasets that cover the satellite era since 1979, is used to diagnosis the moisture budget associated with precipitation changes, determine the onset date of the large-scale monsoonal circulation, and investigate changes in the large-scale atmospheric circulation.

5. Outgoing Longwave Radiation (OLR) from the National Oceanic and Atmospheric Administration (NOAA) is used to study the convection changes, and Extended Reconstructed Sea Surface Temperature version 5 (ERSSTv5) from NOAA is used to examine the sea surface temperature changes related to precipitation changes.

Table 1. Precipitation Datasets Used

\begin{tabular}{llll}
\hline Name & Spatial Resolution & Time Resolution & Time Span \\
\hline GPCP & $2.5^{\circ}$ lat. $\times$ lon. & Monthly, Pentad & $1979-2017$ \\
\hline GPCC & $0.5^{\circ}$ lat. $\times$ lon. & Monthly & $1979-2016$ \\
\hline APHRODITE & $0.25^{\circ}$ lat. $\times$ lon. & Monthly, Daily & $1979-2015$ \\
\hline
\end{tabular}

The non-parametric Mann-Kendall statistical test (Kendall 1948; Kendall 1955) is applied to identify the significance of linear trends, and trends that are statistically significant at the $95 \%$ confidence level are highlighted. It should be noted that the influence of the autocorrelation on the freedom degree has not been considered, because of the short record in this study.

\subsection{Method}

To study mechanisms for the long-term changes in precipitation, we apply the diagnostic computation of the moisture budget (Eq. (1)), which means that precipitation is well balanced with moisture convergence and evaporation on the monthly or longer time scales (Seager et al. 2010; Seager and Henderson 2013; Li et al. 2014; Seager et al. 2014).

$$
\delta P \approx \delta M C+\delta E
$$

where $\delta$ indicates changes in climatic fields, $P$ is precipitation, $E$ is evaporation, $M C$ is the moisture convergence. Specifically, the changes in the moisture convergence $\delta M C$ can be broken down into thermodynamic components involving changes in atmospheric moisture content and dynamic components involving changes in atmospheric motion (Seager and Henderson 2013; Li et al. 2014):

$$
\delta M C=\delta\left(-\frac{1}{g \rho} \nabla \cdot \int_{0}^{p_{s}} \boldsymbol{u} q d p\right) \approx \delta\left(-\frac{1}{g \rho} \nabla \cdot \int_{0}^{p_{s}} \boldsymbol{u}_{c} q_{a} d p\right)+\delta\left(-\frac{1}{g \rho} \nabla \cdot \int_{0}^{p_{s}} \boldsymbol{u}_{a} q_{c} d p\right)
$$

where $g$ is gravitational acceleration, $\rho$ is the density of liquid water, $p$ is pressure, the subscript s denotes surface values, $\boldsymbol{u}$ is horizontal wind vector, $q$ is specific humidity, and the subscript $c$ and $a$ denote climatology and anomalies relative to climatology, respectively. According to Eq. (1) and (2), the changes in precipitation $\delta P$ can be given by Eq. (3):

$$
\delta P \approx \delta\left(-\frac{1}{g \rho} \nabla \cdot \int_{0}^{p_{s}} \boldsymbol{u}_{c} q_{a} d p\right)+\delta\left(-\frac{1}{g \rho} \nabla \cdot \int_{0}^{p_{s}} \boldsymbol{u}_{a} q_{c} d p\right)+\delta E
$$


Here we neglect the quadratic nonlinear term $\delta\left(-\frac{1}{g \rho} \nabla \cdot \int_{0}^{p_{s}} \boldsymbol{u}_{a} q_{a} d p\right)$ that is the product of changes in both the mean specific humidity and flow, as in previous studies (Seager et al. 2010; Seager et al. 2014; Li et al. 2014).

\section{Result}

Quantitative analysis is mainly applied to the Myanmar Coast, which is delimited according to the monsoon division by Wang (2002) and the spatial pattern of climatological monsoon precipitation (Fig. 1). For simplicity, we refer to Myanmar Coast as "MC" hereafter. We first examine recent trends in total monsoon precipitation over MC using all three datasets mentioned above and their ensemble mean. Time series of accumulated precipitation throughout the monsoon season averaged over MC for the period 1979-2015 are shown in Fig. 2a. It shows that total monsoon precipitation exhibit a weak upward trend during $1979-2015$ at the rate of $2.10 \%$ decade $^{-1}$, not reaching the $95 \%$ confidence level. According to the monsoon process, the summer monsoon season of MC can be divided into three phases: onset phase (May), peak phase (June-August), and withdrawal phase (September-October) (Li and Ju 2013; Hrudya et al. 2020). Since the rainfall characteristics of different phases of the monsoon season are different from one another (Hrudya et al. 2020), we further examine trends in accumulated precipitation for each stage of the monsoon season (Figs. 2b-2d). Results show that the total precipitation during the onset and withdrawal phases both have increased significantly at rates of $15.01 \%$ decade $^{-1}$ and $5.76 \%$ decade $^{-1}$ respectively, exceeding the $95 \%$ confidence level, while the total precipitation during the peak phase has decreased slightly (Figs. 2b-2d). Despite discrepancies between inter-annual variability of precipitation from different datasets, there are consistent trends in monsoon precipitation from all three datasets. The three datasets all show significant upward trends in precipitation during the onset and withdrawal phases and non-significant trends in precipitation during the peak phase.
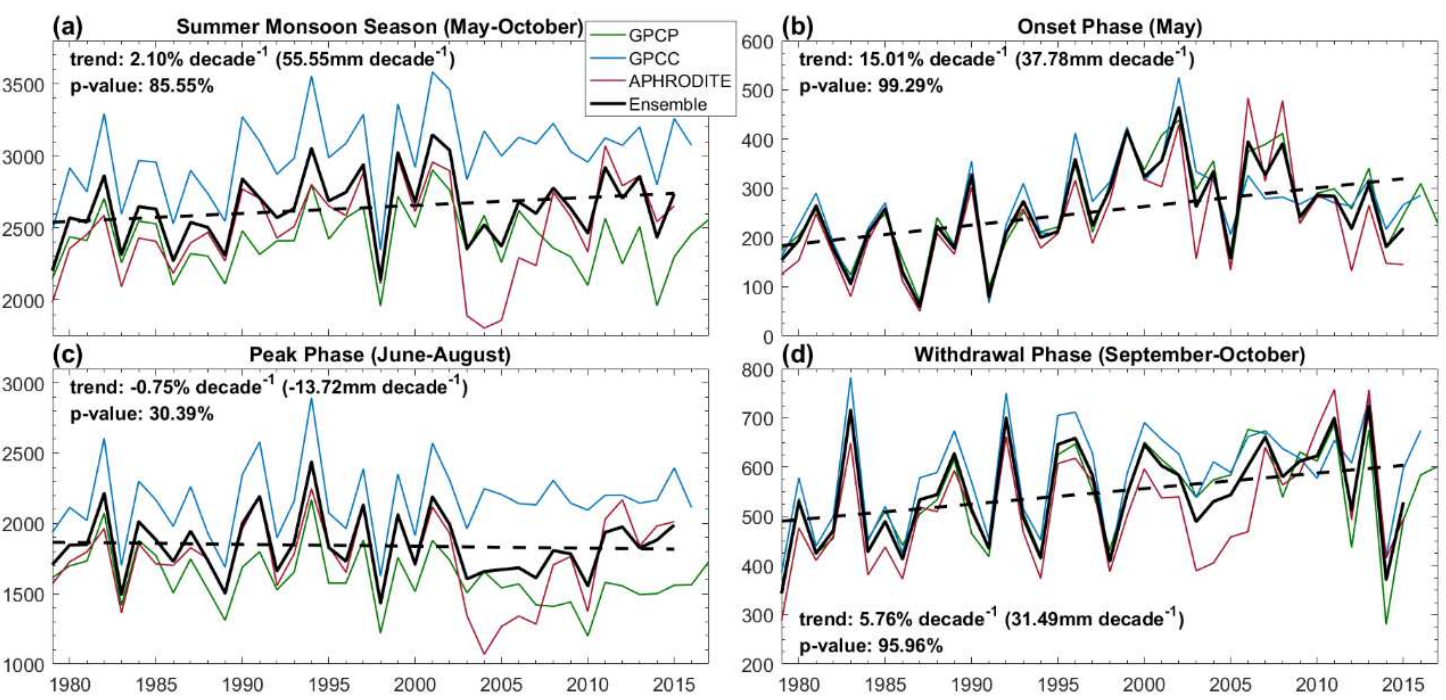

Fig. 2. Time series of accumulated precipitation ( $\mathrm{mm}$ ) during (a) the whole monsoon season, (b-d) the onset, peak, and withdrawal phase of the monsoon season averaged over MC during 1979-2015 from all three precipitation datasets (thin lines), and their ensemble means (thick lines). Dashed black lines indicate the linear fit of precipitation time series, and the trends $\left(\%\right.$ decade $^{-1}$ or $\mathrm{mm}$ decade $\left.{ }^{-1}\right)$ and confidence levels from the Mann-Kendall test are given.

Despite precipitation during the onset and withdrawal phases increase significantly, the increasing 
trend of the total monsoon precipitation is statistically insignificant. This is reasonable due to (1) precipitation decrease during the peak phase offsets part of precipitation increase during the onset and withdrawal phases; (2) total precipitation during the onset and withdrawal phases takes accounts for only $30.25 \%$ of the total monsoon precipitation, trends of the former tend to be not great enough to dominate trends of the latter. It is noteworthy that the contributions of precipitation during the onset and withdrawal phases to total monsoon precipitation have increased by $4.65 \%$ and $2.61 \%$ relative to the climatology during $1979-2015$. Therefore, we focus on the precipitation increase during the two phases in this study. For simplicity, we refer to the onset and withdrawal phases as "MOP", and "MWP" respectively.

The increasing trends of precipitation during MOP and MWP over MC have been further validated by several other precipitation datasets. Results from four other common monthly global gridded precipitation datasets-CPC Merged Analysis of Precipitation, NOAA's Precipitation Reconstruction over Land, Climatic Research Unit, and University of Delaware gauge-based precipitation all show significant increases in accumulated precipitation during MOP and MWP in recent decades over this region (figures not shown).

\section{Explanations for precipitation increase during onset and withdrawal phases}

\subsection{Mechanisms for the precipitation increase during the onset phase}

Figures 3a, 3c, and 3e show the spatial distribution of linear trends in amount, days, and intensity of precipitation during the onset phase (MOP) for the period 1979-2015 from APHRODITE respectively, while the time series of these three variables averaged over MC are shown in Figs. 3b, $3 \mathrm{~d}$, and $3 \mathrm{f}$ respectively. For most of $\mathrm{MC}$, precipitation amount and intensity both exhibit significant upward trends which are spatially consistent (Figs. 3a and 3e). Results show that precipitation amount and intensity averaged in MC both have increased significantly (95\% confidence level; Figs. $3 \mathrm{~b}$ and $3 \mathrm{f})$, at rates of $36.26 \mathrm{~mm} \mathrm{decade}^{-1}\left(15.56 \%\right.$ decade $\left.^{-1}\right)$ and $1.56 \mathrm{~mm}$ day $^{-1}$ decade $^{-1}\left(16.43 \%\right.$ decade $\left.^{-1}\right)$, respectively. Precipitation days didn't change significantly. It demonstrates that the upward trend of precipitation amount during MOP is mainly contributed by the increase of precipitation intensity.
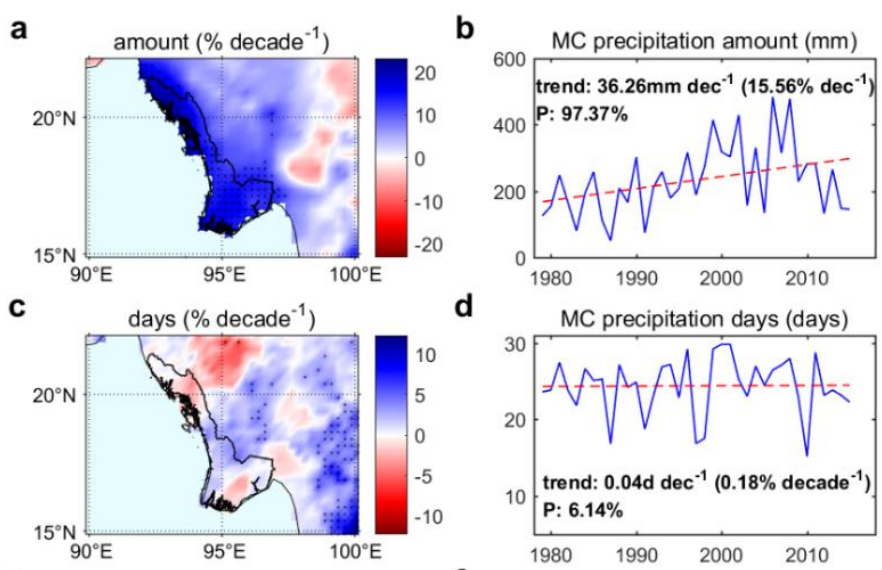

d
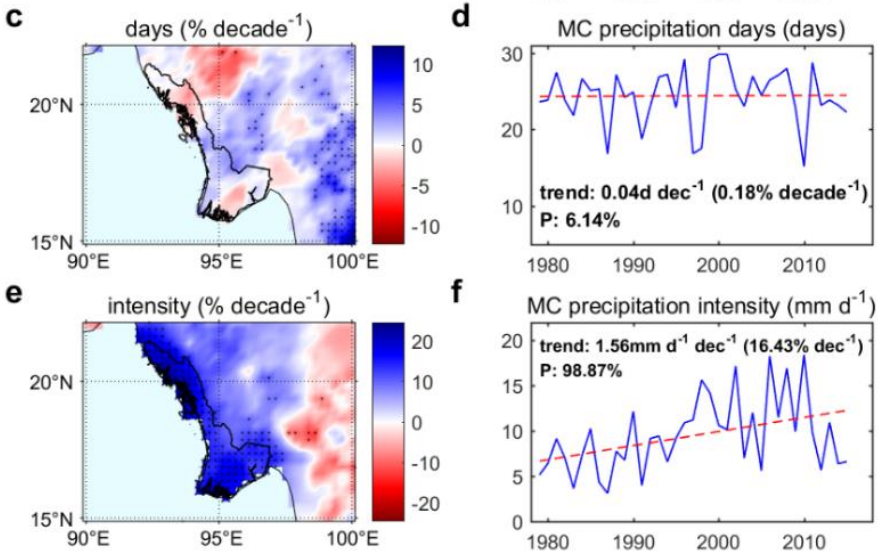
Fig. 3. Linear trends in precipitation (a) amount, (c) days, and (e) intensity during MOP for the period 1979-2015 from APHRODITE (\% decade ${ }^{-1}$ relative to the climatology). Time series of MOP precipitation (b) amount (mm), (d) days (days), and (f) intensity ( $\left.\mathrm{mm} \mathrm{day}^{-1}\right)$ averaged over MC. Dashed red lines are linear fits of the time series.

Daily precipitation from ERA-Interim reanalysis also shows significant increasing trends in amount, and intensity of precipitation during MOP over MC (figures not shown), which is consistent with results from APHRODITE. Moreover, total precipitation during MOP from GPCP and ERA-Interim reanalysis both exhibit significant upward trends around $\mathrm{MC}$ and $\mathrm{BOB}$, which are spatially consistent (Figs. $4 \mathrm{a}$ and $4 \mathrm{~b}$ ).
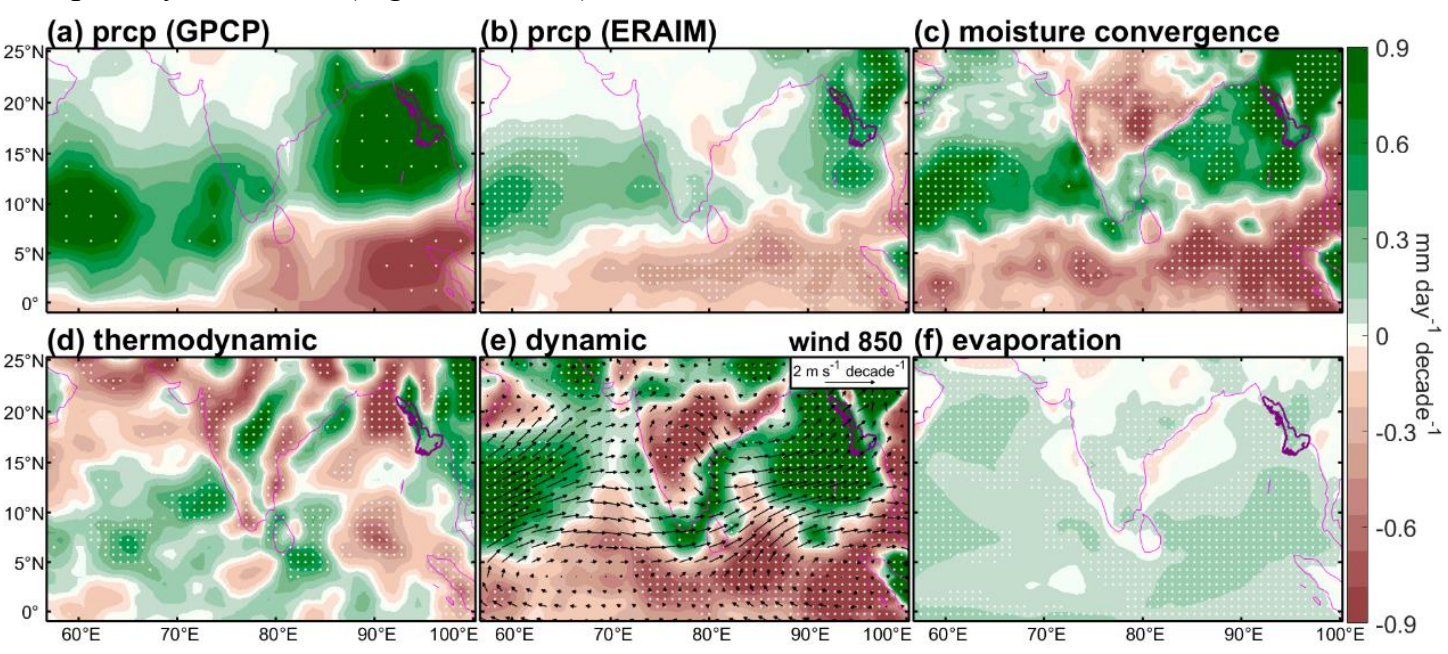

Fig. 4. Linear trends in (a and b) precipitation from GPCP and ERA-interim, respectively, (c) the moisture convergence $\delta\left(-\frac{1}{g \rho} \nabla \cdot \int_{0}^{p_{s}} \boldsymbol{u} q d p\right)$, (d) the thermodynamic component $\delta\left(-\frac{1}{g \rho} \nabla \cdot \int_{0}^{p_{s}} \boldsymbol{u}_{c} q_{a} d p\right)$, (e) the dynamic component $\delta\left(-\frac{1}{g \rho} \nabla \cdot \int_{0}^{p_{s}} \boldsymbol{u}_{a} q_{c} d p\right)$, and (f) evaporation during MOP for the period 1979-2015 (shading, mm day $^{-1}$ decade $\left.{ }^{-1}\right)$. Vectors in Fig. $4 \mathrm{e}$ are linear trends in $850-\mathrm{hPa}$ horizontal winds $\left(\mathrm{m} \mathrm{s}^{-1}\right.$ decade $\left.^{-1}\right)$. White dots indicate the $95 \%$ confidence level.

Precipitation derived from ERA-Interim reanalysis exhibits trends spatially consistent with that from GPCP over the SASM region despite the magnitude is underestimated, which consolidates the reliability of trend analysis using ERA-Interim reanalysis. To explore the physical mechanisms for recent trends of precipitation during MOP, we compute trends of each component in the atmospheric moisture budget using data from ERA-Interim reanalysis and the method described in Section 2.2. Results show that trends in moisture convergence $\delta\left(-\frac{1}{g \rho} \nabla \cdot \int_{0}^{p_{s}} \boldsymbol{u} q d p\right)$ agree well with those in precipitation in terms of their magnitude and spatial distribution in the SASM region; particularly, they both show significant increasing trends over MC and BOB (Figs. 4b and 4c). And evaporation trends exhibit relatively weak magnitude and inconsistent spatial distribution with precipitation trends. This indicates that trends of precipitation are mainly caused by those in moisture convergence while those in evaporation play a minor role. By comparing Figs. $4 \mathrm{c}, 4 \mathrm{~d}$ and $4 \mathrm{e}$, we observe that the dynamic contributors $\delta\left(-\frac{1}{g \rho} \nabla \cdot \int_{0}^{p_{s}} \boldsymbol{u}_{a} q_{c} d p\right)$, i.e., the changes of atmospheric motion, play a leading role in trends in moisture convergence over large parts of the $\mathrm{SASM}$ region, including $\mathrm{MC}$ and $\mathrm{BOB}$, while the thermodynamic contributors $\delta\left(-\frac{1}{g \rho} \nabla\right.$. 
$\left.\int_{0}^{p_{s}} \boldsymbol{u}_{c} q_{a} d p\right)$, i.e., the changes in atmospheric moisture content, contribute less. Therefore, we conclude that the precipitation increase during MOP over MC is mainly caused by the increase in moisture convergence especially the dynamic component involving changes in atmospheric motion.

To further study the changes in atmospheric motion that lead to the trends in moisture convergence over MC, we examine the recent trend in $850-\mathrm{hPa}$ horizontal wind, which is shown in Fig. 4e. It is observed that significant increasing trends of cross-equatorial flow and low-level southwesterly wind during MOP in recent decades occur around the northern Indian Ocean, which tend to strengthen the monsoon circulation in the SASM region. The low-level southwesterly wind increase plays an important role in the increase in moisture convergence and hence that in precipitation over MC in recent decades.

Climatologically, May is the onset date of the SASM, i.e., the transition phase from low-level easterly winds to southwesterly winds over the northern Indian Ocean. The strengthening of the southwesterly wind during MOP typically results from either an earlier onset of the SASM or the intensifying of the southwesterly wind after the monsoon onset. Since the meridional sea-land thermal difference dominates the SASM region and directly affects the onset of the SASM onset (Li 1996; Ueda 2009; Kong and Yu 2012), we further examine the recent trend of tropospheric temperature reflected by the atmospheric thickness between $500 \mathrm{hPa}$ and $200 \mathrm{hPa}$ during the period 1979-2015, which is shown in Fig. 5. It is observed that tropospheric temperature has increased in most of the SASM region, which is consistent with many previous studies. And troposphere over the Asian continent has warmed faster than that over the Indian Ocean (Fig. 5), which favors an earlier overturning of sea-land thermal difference in the pre-monsoon days and thus an earlier monsoon onset. We also compute trends in 200-hPa horizontal winds for 1979-2015 and show them in Fig. 5. It illustrates that significant upper-level anticyclone circulation intensifying occur around northern India (Fig. 5), which favors stronger updrafts over this region including $\mathrm{MC}$ and thus strengthens the monsoon circulation. Both the meridional sea-land warming difference and enhanced low-level southwesterly during MOP imply that the onset of SASM may have advanced in recent decades.

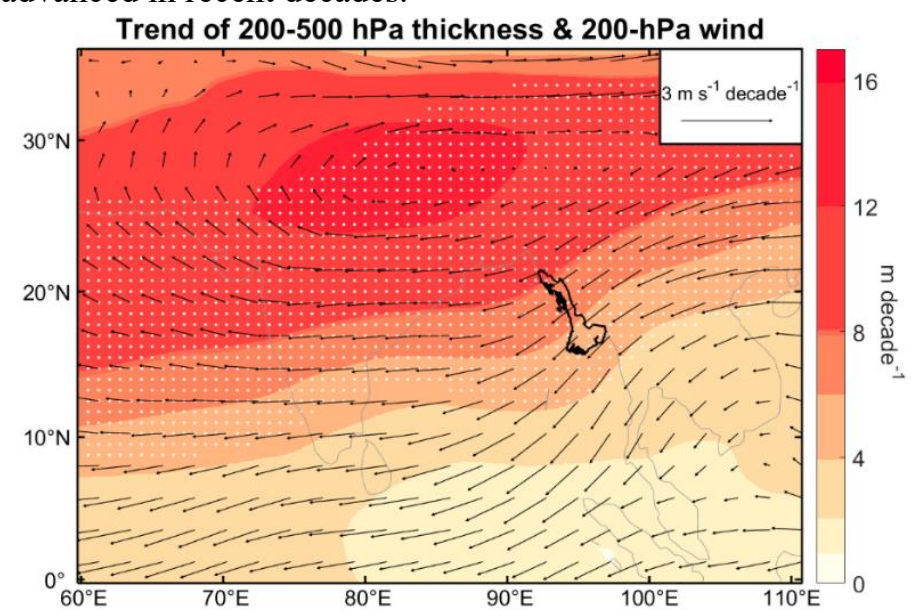

Fig. 5. Linear trends of atmosphere thickness between $500 \mathrm{hPa}$ and $200 \mathrm{hPa}$ (shading, $\mathrm{m} \mathrm{decade}^{-1}$ ) during MOP for the period 1979-2015. Vectors indicate linear trends of 200-hPa horizontal winds $\left(\mathrm{m} \mathrm{s}^{-1}\right.$ decade $\left.^{-1}\right)$ during MOP during 1979-2015. White dots denote the $95 \%$ confidence level.

We further investigate the long-time change of monsoon onset and explore its impact on 
precipitation during MOP over MC. Here we use two monsoon onset indexes, which are shown in Fig. 6. One is the change point (CHP) index for overall SASM onset, which is calculated using the method from Cook and Buckley (2009). The CHP index has been proven to have numerous advantages in defining seasonal monsoon transitions and be suitable for the SASM region (Walker and Bordoni 2016). We compute the CHP onset date in each year using moisture divergence from ERA-interim reanalysis. The other index is the local onset date of the summer monsoon over MC, which is determined using pentad precipitation data from GPCP and the method from Wang (2002). It should be noted that the local monsoon circulation directly affects MOP precipitation over MC (Aung et al. 2017). Results show that in climatology the summer monsoon bursts around 11 May over MC, which is consistent with the results of Watanabe and Yamazaki (2014). It also indicates that the local onset of summer monsoon has advanced by about 17 days in recent decades (Fig. 6). Precipitation during MOP over MC increases along with the earlier onset of the monsoon during 1979-2015, and temporal variations of MOP precipitation and the monsoon onset date match well with each other (Fig. 6). The correlation coefficient of these two indices reaches -0.71 , statistically significant at the $95 \%$ confidence level. Results demonstrate that the SASM onset also has advanced and its dates agree well with the local monsoon onset dates in MC during 1979-2015 (Fig. 6), which is reasonable since this coastal region is typically the land that the SASM first break out. And a significant correlation coefficient of -0.74 ( $95 \%$ confidence level) is also detected between MOP precipitation over MC and the SASM onset dates. Thus, recent trends of MOP precipitation over MC and the monsoon onset, as well as their tight relationship, are robustly confirmed using the above two independent indexes.

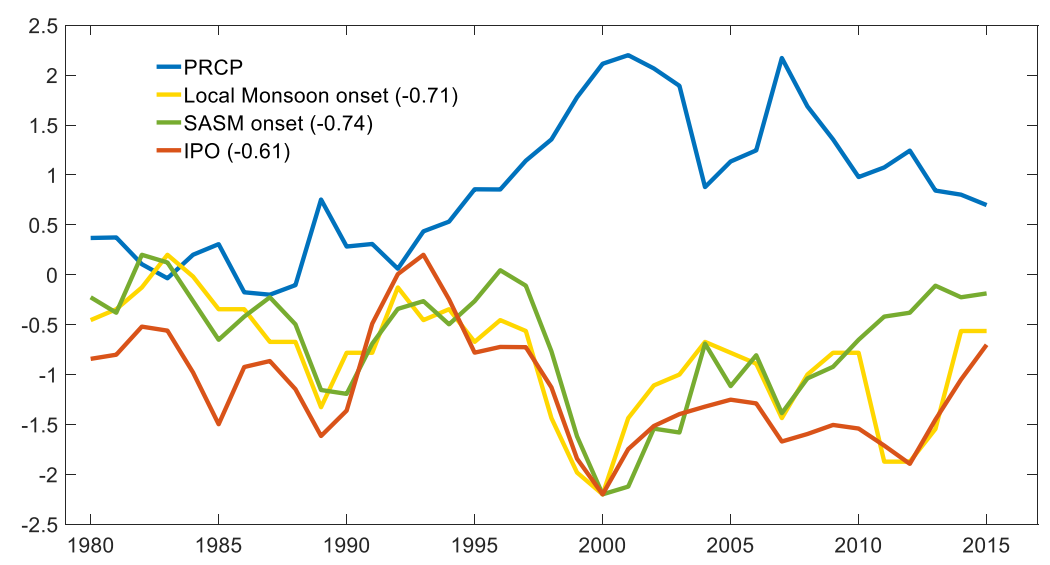

Fig. 6. Normalized and 3 years moving average time series of MOP precipitation over MC (blue), the local onset date of the summer monsoon over MC (yellow), the SASM onset date (green), and the IPO Tripole Index for the onset phase (red). Correlation coefficients between precipitation and other indexes are given in parentheses. It should be noted that the correlation coefficients are estimated using the non-smoothed time series.

Based on the above results, we conclude that the increasing trend of precipitation during MOP over MC is directly caused by the advance of SASM onset since 1979. Now a new question arises is-What has led to the advanced monsoon onset? To explore the answer, we examine the correlation between the monsoon onset date over MC and the sea surface temperature (SST) anomalies in the Pacific and Indian oceans, which is shown in Fig. 7a. It is observed that the most significant positive and negative correlation appears in the central-eastern Pacific and in the northwest and southwest Pacific, respectively, which together exhibit an Inter-decadal Pacific Oscillation (IPO)-like pattern. It indicates that the monsoon onset typically breaks out early (late) 
in the negative (positive) IPO phase.

Several previous studies have documented the dynamic mechanisms of interdecadal variability in the Pacific Ocean affecting the onset of the Asian summer monsoon (Kong and Yu 2012; Xiang and Wang 2013; Watanabe and Yamazaki 2014). Watanabe and Yamazaki (2014) demonstrate that anomalous northern Pacific Ocean SST similar to that in the negative Pacific Decadal Oscillation phase intensifies land-sea thermal contrast in the Asian summer monsoon region via a stationary wave train propagating to central Asia, and thus promotes the advanced SASM onset in recent decades. Xiang and Wang (2013) prove that the earlier onset of the Asian summer monsoon since the late 1970 s is mainly caused by a "grand" La Nina-like mean state change in the Pacific basin in the 1990s through the westward propagation of Rossby waves. Specifically, the advanced monsoon onset in BOB is proven caused by the enhanced zonal SST gradients in the equatorial Pacific (Xiang and Wang 2013).

Based on these widely acknowledged mechanisms, we further explore whether IPO affects MOP precipitation over MC by influencing the summer monsoon onset. We regress SST anomalies onto MOP precipitation over MC, as shown in Fig. 7b. Results show that the correlation between the two features a negative IPO pattern, which implies that MOP precipitation over MC tends to increase (decrease) in the negative (positive) IPO phase. Furthermore, we examine the correlation between MOP precipitation over MC and an IPO Tripole Index, which is defined by Henley (2015) as the difference between SST anomalies averaged over the central equatorial Pacific and that over the northwest and southwest Pacific, as shown in Fig. 7. It indicates that the two indexes show a significant negative correlation, with a correlation coefficient of -0.61 ( $95 \%$ confidence level; Fig. $6)$.

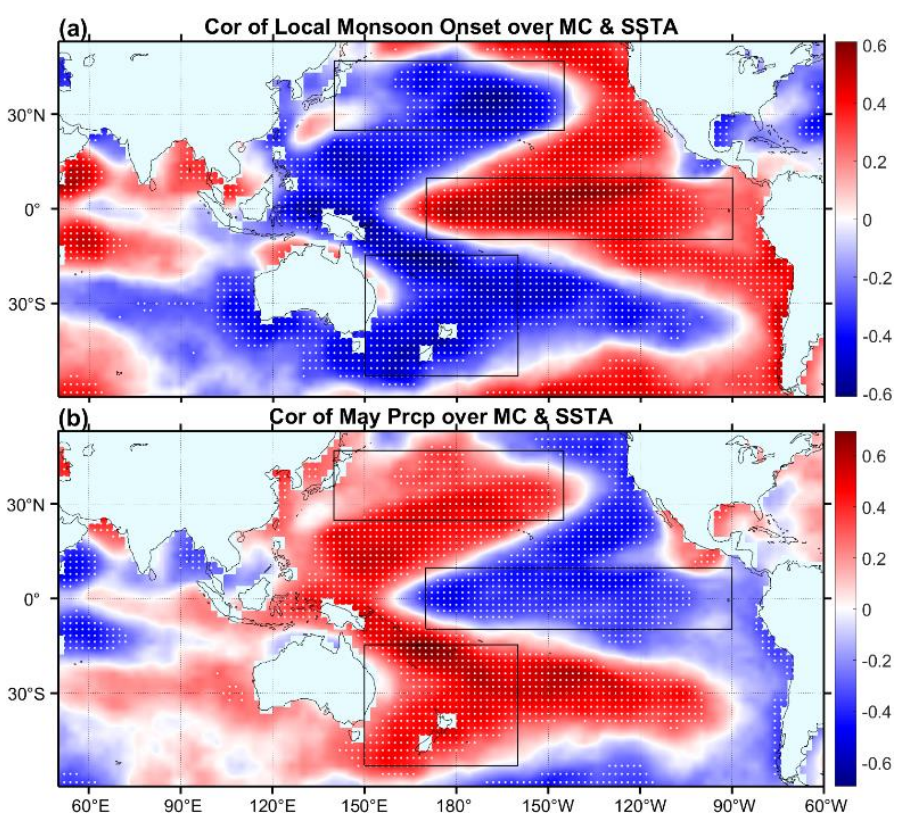

Fig. 7. The correlation coefficients between SST anomalies during MOP with (a) the local onset date of the summer monsoon and (b) MOP precipitation over MC. White dots indicate the $95 \%$ confidence level. Black boxes denote the northwest $\left(25^{\circ}-45^{\circ} \mathrm{N}, 140^{\circ} \mathrm{E}-145^{\circ} \mathrm{W}\right)$, southwest $\left(50^{\circ}-15^{\circ} \mathrm{S}, 150^{\circ} \mathrm{E}-160^{\circ} \mathrm{W}\right)$, and central equatorial Pacific $\left(10^{\circ} \mathrm{S}-10^{\circ} \mathrm{N}, 170^{\circ} \mathrm{E}-90^{\circ} \mathrm{W}\right)$.

We also test the mutation of the monsoon onset dates and MOP precipitation over MC during 1979-2015 using the Lepage test (LEPAGE 1971; Liu et al. 2011) and the moving t-test (Xiao and Li 2007). Results show that the two indices both exhibit robust decadal shifts in 1999, which are 
corresponding to the phase transition of the IPO at the same time (Fig. 8). The abrupt decadal shifts of these three indices in the late 1990s are statistically significant at the $95 \%$ confidence level, using the Mann-Kendall test. Thus, we conclude that fundamentally the phase transition of the IPO in the late 1990s drives the advanced onset of the SASM and thus triggers the increase in MOP precipitation over MC in recent decades.
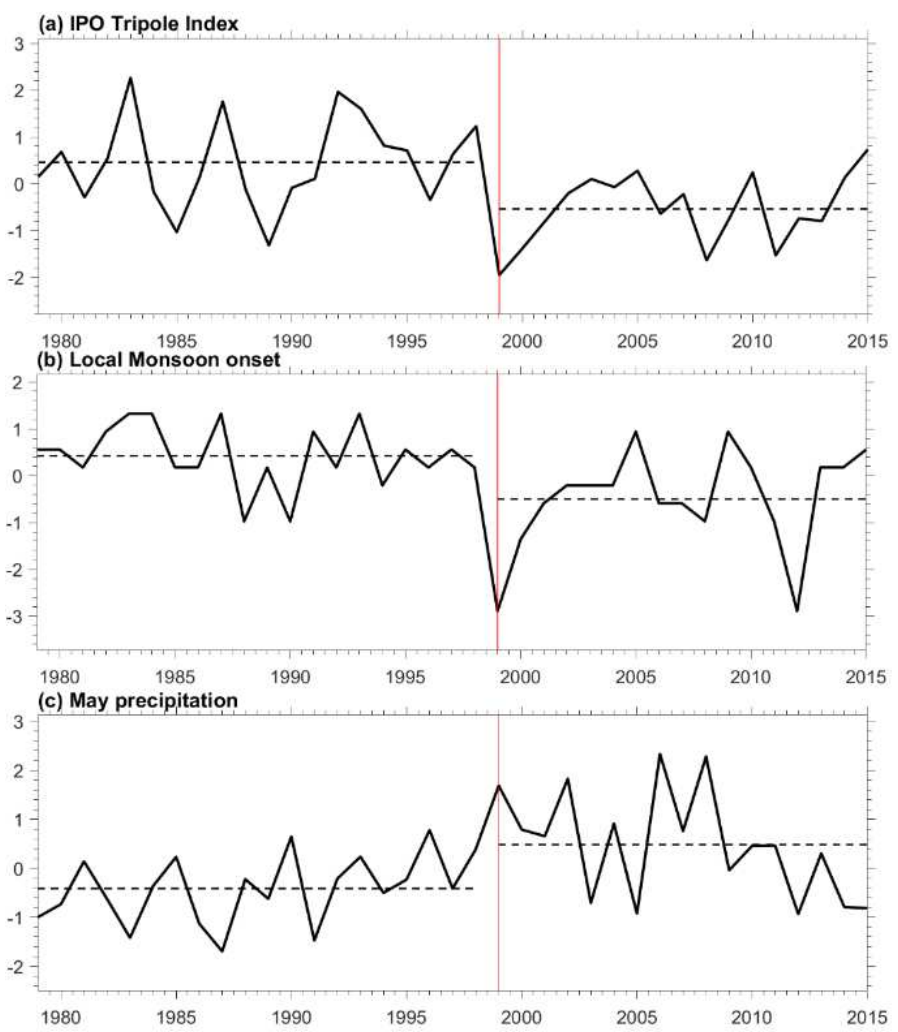

Fig. 8. The normalized (a) IPO Tripole Index, (b) summer monsoon onset date over MC, and (c) MOP precipitation over MC for the period 1979-2015. The black dashed lines denote the mean value of these indices at each epoch separated by 1999.

\subsection{Mechanisms for the precipitation increase during the withdrawal phase}

To investigate the precipitation increase during the withdrawal phase (MWP), we first examine trends in precipitation amount, days, and intensity during MWP for the period 1979-2015 using daily precipitation from APHRODITE (Fig. 9). It is observed that precipitation amount and intensity during MWP both show significant increasing trends over most of MC, and trends of the two agree well in spatial patterns (Figs. 9a and 9e). And regional averaged precipitation amount and intensity both exhibit prominently upward trends which are statistically significant at the $95 \%$ confidence level (Figs. 9b and 9f), and their linear trends are $39.64 \mathrm{~mm} \mathrm{decade}^{-1}\left(7.72 \%\right.$ decade $\left.^{-1}\right)$ and $0.79 \mathrm{~mm} \mathrm{day}^{-1}$ decade $^{-1}\left(8.03 \%\right.$ decade $\left.^{-1}\right)$, respectively. Meanwhile, precipitation days show no significant trends (Figs. 9c and 9d). It indicates that the increase of precipitation amount during MWP is mainly caused by the increase of precipitation intensity. 

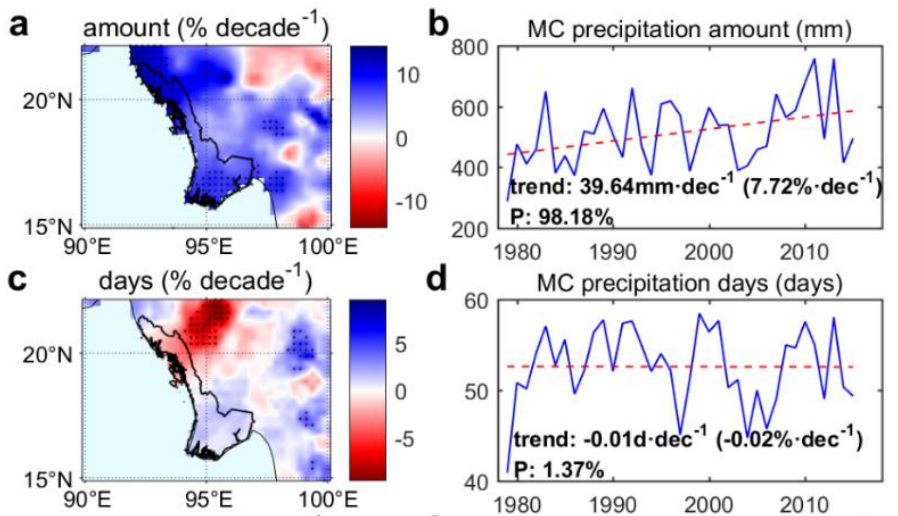

d
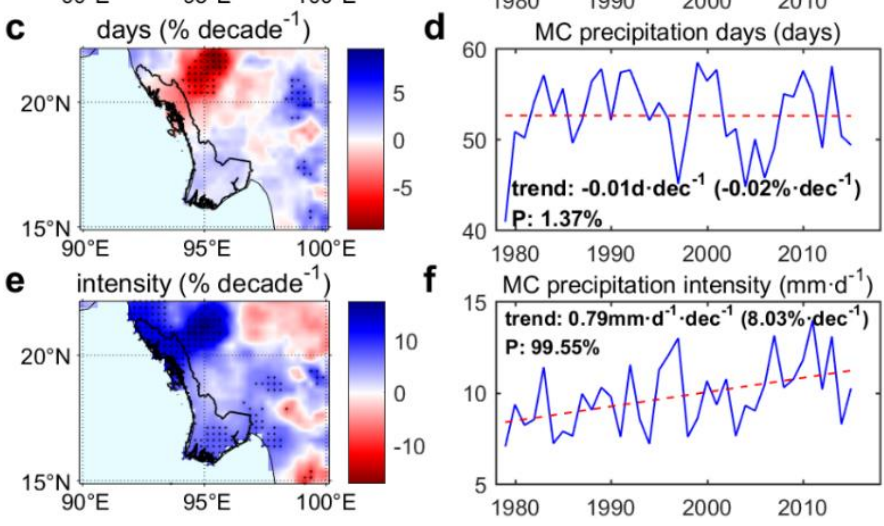

Fig. 9. Same as in Fig. 3 but for MWP.

354

355

356

357

358

359

Daily precipitation from ERA-Interim also shows that precipitation amount and intensity during MWP over MC both have increased significantly (figures not shown), which consolidates results from APHRODITE. Total precipitation during MWP from GPCP and ERA-Interim both manifest significant increasing trends around $\mathrm{MC}$ and $\mathrm{BOB}$, and precipitation trends derived from the two datasets agree well in spatial patterns (Figs. 10a and 10b).

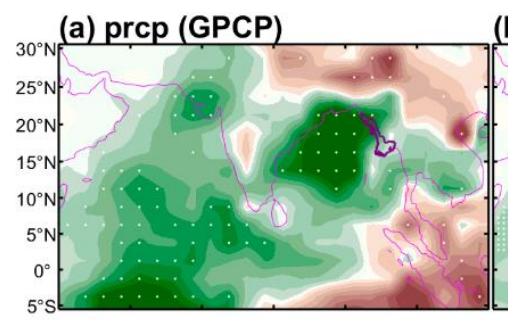

(b) prcp (ERAIM)

(c) moisture convergence

(d) thermodynamic

(e) dynamic
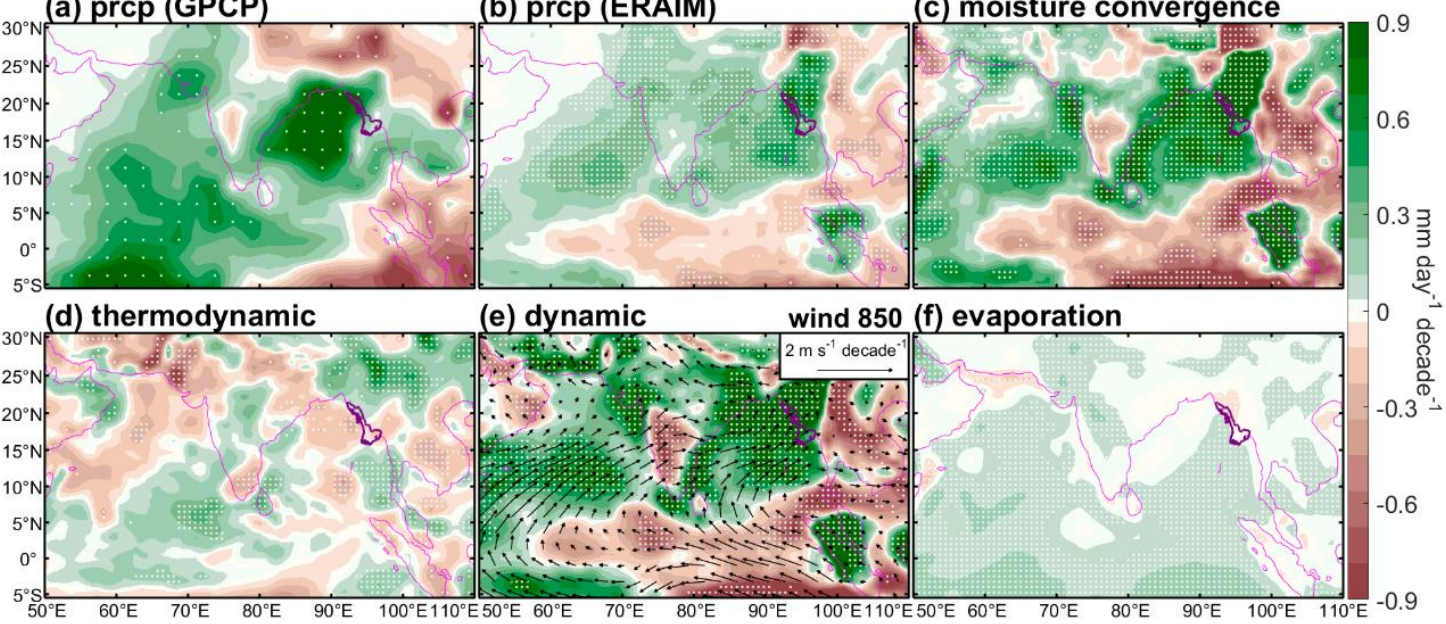

Fig. 10. Same as in Fig. 4 but for MWP.

To explore the dominant physical mechanisms for precipitation changes during MWP, we examine changes in the moisture budget in the same way as in Section 4.1 and show results in Fig. 10. It demonstrates that evaporation during MWP shows weak decreasing trends over MC, which doesn't contribute to the precipitation increase. Meanwhile, moisture convergence during MWP exhibits significant increasing trends around $\mathrm{MC}$ and $\mathrm{BOB}$, and its trends show similar magnitude and spatial patterns with precipitation trends over the SASM region (Figs. 10b and 10c). This implies that moisture convergence changes play a dominant role in the precipitation increase during MWP. Furthermore, it is observed that trends in moisture convergence during MWP are mainly contributed by the dynamic component over most of the SASM region including MC, while the thermodynamic component plays a minor role (Figs. 10c, 10d, and 10e). Thus we 
conclude that the increase in precipitation during MWP over MC is mainly caused by the increase in the dynamic component of moisture convergence, i.e., changes in atmospheric motion.

To further study how the atmospheric motion changes during MWP over MC, we calculate trends in $850-\mathrm{hPa}$ horizontal wind during MWP and show results in Fig. 10e. Accompanied by the strengthening of cross-equatorial flow around the equatorial western and eastern Indian Ocean, the low-level southwesterly intensifying during MWP appears around the Arabian Sea and BOB in the past decades, which is consistent with the moisture convergence increasing over the region (Fig. 10e). And the southeasterly strengthening is observed around the south of the Himalayas, which together with the southwesterly strengthening over BOB comprises an anomalous cyclone-like circulation. This anomalous cyclone-like circulation implies the intensifying of the monsoon trough around the $\mathrm{BOB}$, which facilitates the increase of moisture convergence and thus that of precipitation over this region. In addition, the latent heating induced by the increasing precipitation can induce a Rossby wave atmospheric response to the west (Matsuno 1966; Gill 1980), which would enhance the low-level southwesterly around BOB (Hu et al. 2019).

Since the monsoon circulation exhibits a three-dimensional structure, we further examine changes in mid-and upper-level circulation. Figure 11a shows trends of 500-hPa vertical velocities and OLR during MWP in the past decades. Significant enhancements in the ascending motion and convection are observed over $\mathrm{MC}$ and $\mathrm{BOB}$, while significant descending motion strengthening and convection weakening occur around the southeastern Tibetan Plateau. This trend pattern of vertical velocities implies the strengthening of the meridional circulation cell around BOB, which is climatologically characterized by ascending motion south of the Himalayas and descending motion over the Tibetan Plateau (Li and Ju 2013). By comparing Fig.10b and 11a, we observe that the trend patterns of 500-hPa vertical velocities and OLR are both largely consistent with that of precipitation during MWP.

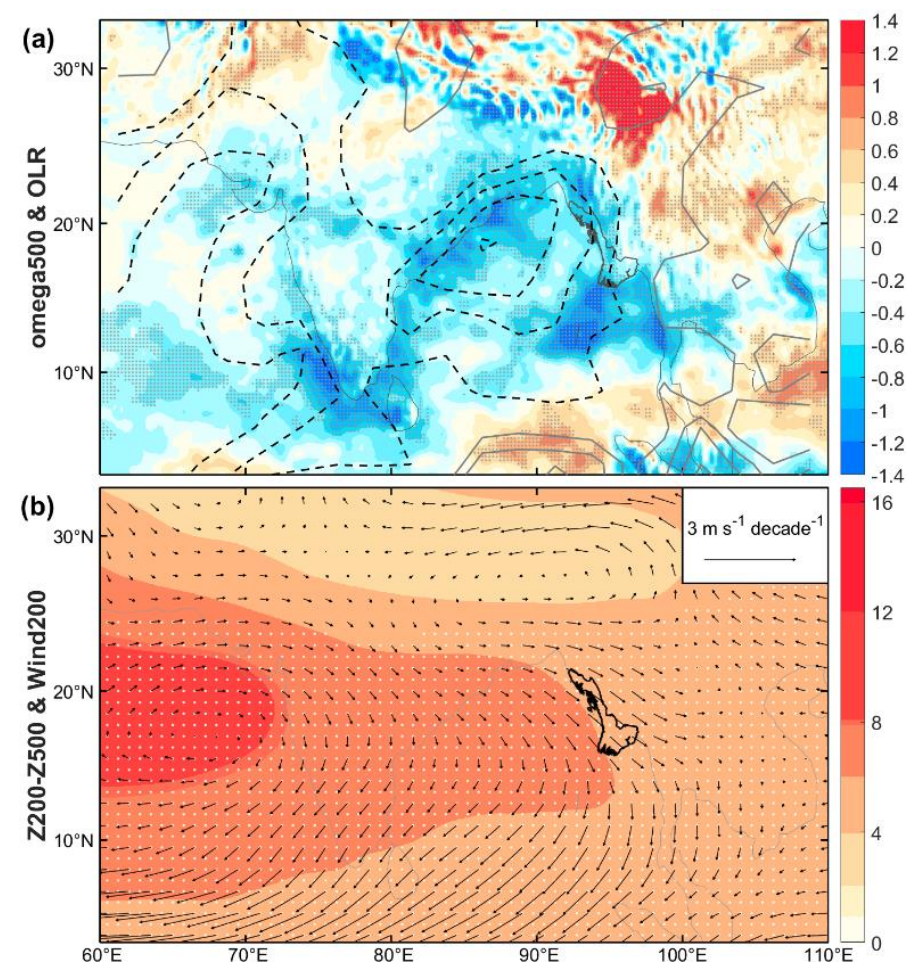

Fig. 11. Linear trends of (a) 500-hPa vertical velocities (shading, $10^{-4} \mathrm{hPa} \mathrm{s}^{-1}$ decade $^{-1}$ ) and OLR (contour, $\mathrm{W} \mathrm{m}^{-2}$ 
decade $^{-1}$ ) during MWP for the period 1979-2015. Dots denote the 95\% confidence level.

We also compute linear trends in atmosphere thickness of $200 \mathrm{hPa}-500 \mathrm{hPa}$ and 200-hPa horizontal wind during MWP and show results in Fig. 11b. It shows that tropospheric temperature during MWP in most of the SASM region has warmed in recent decades. And the most significant warming appears around the Arabian Sea, Indian sub-continent, and BOB (Fig. 11b), which favors stronger updrafts and thus strengthens the monsoon circulation over the regions including $\mathrm{MC}$. Meanwhile, an anomalous anticyclone at $200 \mathrm{hPa}$ is located over these regions (Fig. 11b), implying stronger upper-level divergence and thus promoting the intensifying of the ascending motion. And an anomalous upper-level cyclone is observed around the southern Tibetan Plateau, which favors stronger descending motion over this region. Both the warming difference and anomalous upper-level circulation are favorable for the strengthening of the monsoon circulation. Based on the above results, we infer that the precipitation increase during MWP over MC is directly due to the enhances of the ascending motion and convection around this region, which is dynamically correlated to the anomalous cyclone-like circulation around the BOB as well as the strengthening of the cross-equatorial flow around the equatorial Indian Ocean.

\section{Discussion}

The study for MWP mainly addresses the internal atmospheric causes, and the possible external forcing remains to be explored. We examine the correlation of SST anomalies with precipitation during MWP over MC for 1979-2015, which is shown in Fig. 12. Results show that contrary to MOP, SST anomalies in southern Arabia and southern BOB exhibit positive correlation with precipitation during MWP (Fig. 12), which along with results of tropospheric temperature (Fig. 11b) implies that anomalous SST over Arabia and BOB may be an important forcing for the precipitation increase during MWP. By compared Figs. 7b and 12, we observe that the influence of Pacific Ocean SST on precipitation during MWP also shows a La Nina-like pattern but smaller magnitude than that during MOP. Meanwhile, SST anomalies in the eastern Indian Ocean and the sea around Indonesia during MWP show a more significant influence, which is largely consistent with results in Sabeerali et al. (2012). Previous studies also reported the La Nina-like Pacific SST trend/interdecadal change, the eastern Indian Ocean SST increasing, and the strengthening and the westward shift of the Walker Circulation as a response to this anomalous SST forcing (Xiang and Wang 2013; Ma and Zhou 2016). These along with our results (Fig. 12) imply that the SST change in the Pacific and eastern Indian Ocean may be a crucial external forcing for the atmospheric circulation changes and the precipitation increase during MWP around MC. The detailed physical mechanisms for the impact of SST changes in the Pacific and the Indian Ocean on precipitation during MWP will be further pursued in the future.

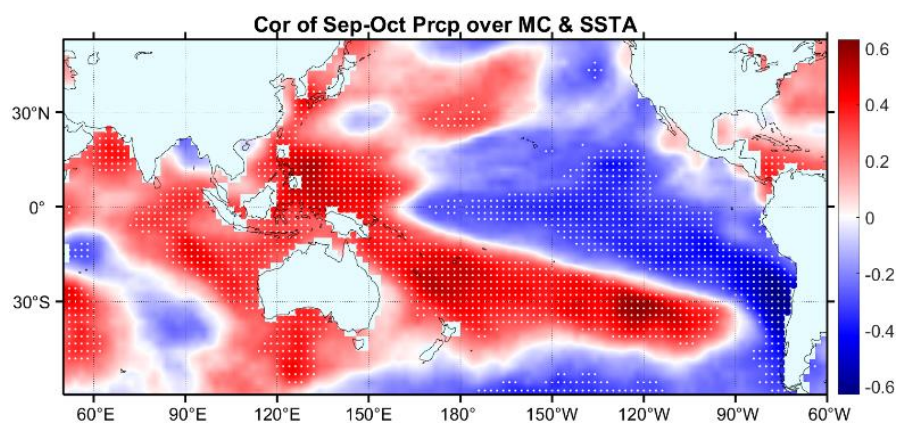

Fig. 12. The correlation coefficients between SST anomalies during MOP with (a) the local onset date of the 
summer monsoon and (b) MOP precipitation over MC. White dots indicate the $95 \%$ confidence level.

The variability of the summer monsoon and the seasonality of monsoon precipitation trends over $\mathrm{MC}$ is expected to affect vegetation growing and thus the rain-fed agriculture as well as regional hydrology. For instance, the majority of plantation crops are likely to benefit due to the increase in rainfall during MWP. On the other hand, this region is vulnerable to hydrological and meteorological disasters. Several previous studies reported tropical cyclones (TCs) in the BOB had intensified during the onset and withdrawal phases in recent decades and had a stronger impact on MC (Wang et al. 2013; Balaguru et al. 2014; Fosu and Wang 2015; Albert and Bhaskaran 2020; Jyoteeshkumar Reddy et al. 2021). Our results show similar change patterns in atmospheric circulation during the onset and withdrawal phases to results from Wang et al. (2013) and Fosu and Wang (2015), which are proven responsible for the TCs intensifying. Therefore, it deserves further study to assess and understand changes in BOB TCs and their contribution to changes of precipitation, especially heavy precipitation during the onset and withdrawal phase over MC.

\section{Conclusion}

In this study, we focus on recent trends in precipitation in the monsoon season over MC, which is an important rice-producing region in the world and the front land in the SASM region. Results from multiple precipitation datasets show that total precipitation in the monsoon season has increased slightly but not significantly, but precipitation during the onset and withdrawal phase of monsoon season over this region exhibits a significant increasing trend in recent decades. And the contribution of precipitation during the two phases to total monsoon precipitation both exhibit a significant upward trend. We examine recent trends in moisture budget related to the precipitation change during the two phases using ERA-interim reanalysis data. Results show that the dynamic component of moisture convergence plays a dominant role in the precipitation increase during the two phases, while changes in thermodynamic component and evaporation both contribute relatively little. By analyzing changes in atmospheric circulation, we infer that the upward trends in precipitation during MOP directly result from the advanced onset of the SASM. With the advanced onset of the SASM, the enhanced monsoon circulation during MOP promotes the intensified local moisture convergence, leading to increased precipitation over MC. Fundamentally, the advance of the SASM onset is triggered by the phase transition of IPO in the 1990s. And we conclude that the precipitation increase during MWP is directly due to the enhances of the ascending motion and convection around this region, which is dynamically correlated to the anomalous cyclone-like circulation around $\mathrm{BOB}$ as well as the strengthening of the cross-equatorial flow around the equatorial Indian Ocean.

\section{Author's Contribution}

Xiao Yan and Yibin Yao performed background research and designed the study with input from Yuanjian Yang and Bao Zhang. Liang Zhang led the precipitation data collecting and preprocessing. Xiao Yan designed the figures with additional data prepared by Yuanjian Yang. Xiao Yan and Yibin Yao wrote the manuscript. All authors discussed the results and commented on the manuscript.

\section{Data availability}

All the data used in this research are available in the public domain at the links provided in the 
texts.

\section{Code availability}

The code used in this research will be available (by the corresponding author), upon reasonable request.

\section{Ethics approval and consent to participate}

The authors confirm that this article is original research and has not been published or presented previously in any journal or conference in any language.

\section{Consent for publication}

All the authors consented to publish the paper.

\section{References:}

Adler, R.F., Huffman, G.J., Chang, A., Ferraro, R., Xie, P., Janowiak, J., Rudolf, B., Schneider, U., Curtis, S., Bolvin, D., Gruber, A., Susskind, J., Arkin, P., \& Nelkin, E. (2003). The Version-2 Global Precipitation Climatology Project (GPCP) Monthly Precipitation Analysis (1979 - Present). JOURNAL OF HYDROMETEOROLOGY, 4, 1147-1167

Albert, J., \& Bhaskaran, P.K. (2020). Ocean heat content and its role in tropical cyclogenesis for the Bay of Bengal basin. CLIMATE DYNAMICS, 55, 3343-3362

Aung, L.L., Zin, E.E., Theingi, P., Elvera, N., Aung, P.P., Han, T.T., Oo, Y., \& Skaland, R.G. (2017). Myanmar Climate Report. In: Norwegian Meteorological Institute

Balaguru, K., Taraphdar, S., Leung, L.R., \& Foltz, G.R. (2014). Increase in the intensity of postmonsoon Bay of Bengal tropical cyclones. GEOPHYSICAL RESEARCH LETTERS, 41, 3594-3601 Bollasina, M.A., Ming, Y., \& Ramaswamy, V. (2011). Anthropogenic Aerosols and the Weakening of the South Asian Summer Monsoon. SCIENCE, 334, 502-505

Chan, J.C.L., \& Zhou, W. (2005). PDO, ENSO and the early summer monsoon rainfall over south China. GEOPHYSICAL RESEARCH LETTERS, 32

Chhin, R., Shwe, M.M., \& Yoden, S. (2020). Time-lagged correlations associated with interannual variations of pre-monsoon and post-monsoon precipitation in Myanmar and the Indochina Peninsula. INTERNATIONAL JOURNAL OF CLIMATOLOGY, 40, 3792-3812

Cook, B.I., \& Buckley, B.M. (2009). Objective determination of monsoon season onset, withdrawal, and length. Journal of Geophysical Research: Atmospheres, 114

Fosu, B.O., \& Wang, S.S. (2015). Bay of Bengal: coupling of pre-monsoon tropical cyclones with the monsoon onset in Myanmar. CLIMATE DYNAMICS, 45, 697-709

Gadgil, \& Sulochana (2004). Extremes of the Indian summer monsoon rainfall, ENSO and equatorial Indian Ocean oscillation. GEOPHYSICAL RESEARCH LETTERS, 31, 179-206

Ghosh, S., Luniya, V., \& Gupta, A. (2009). Trend analysis of Indian summer monsoon rainfall at different spatial scales. Atmospheric Science Letters, 10, 285-290

Gill, A.E. (1980). Some simple solutions for heat-induced tropical circulation. QUARTERLY JOURNAL OF THE ROYAL METEOROLOGICAL SOCIETY, 106, 447-462

Henley, B.J. (2015). A Tripole Index for the Interdecadal Pacific Oscillation. CLIMATE DYNAMICS, $v$. 45, 3077-3090

Hrudya, P.H., Varikoden, H., Vishnu, R., \& Kuttippurath, J. (2020). Changes in ENSO-monsoon relations from early to recent decades during onset, peak and withdrawal phases of Indian summer monsoon. CLIMATE DYNAMICS, 55, 1457-1471 
Hu, P., Chen, W., \& Chen, S. (2019). Interdecadal change in the South China Sea summer monsoon withdrawal around the mid-2000s. CLIMATE DYNAMICS, 52, 6053-6064

Huang, Y., Wang, B., Li, X., \& Wang, H. (2018). Changes in the influence of the western Pacific subtropical high on Asian summer monsoon rainfall in the late 1990s. CLIMATE DYNAMICS, 51, 443-455

Huffman, G.J., Adler, R.F., Bolvin, D.T., \& Gu, G. (2009). Improving the global precipitation record: GPCP Version 2.1. GEOPHYSICAL RESEARCH LETTERS, 36

Jyoteeshkumar Reddy, P., Sriram, D., Gunthe, S.S., \& Balaji, C. (2021). Impact of climate change on intense Bay of Bengal tropical cyclones of the post-monsoon season: a pseudo global warming approach. CLIMATE DYNAMICS

Kajikawa, Y., \& Wang, B. (2012). Interdecadal Change of the South China Sea Summer Monsoon Onset *. JOURNAL OF CLIMATE, 25, 3207-3218

Kendall, M.G. (1948). Rank correlation methods. Oxford, England: Griffin

Kendall, M.G. (1955). Rank correlation methods, 2nd ed. Oxford, England: Hafner Publishing Co.

Kong, D., \& Yu, K.Y.S. (2012). Interdecadal Change of the South China Sea Summer Monsoon Onset *. JOURNAL OF CLIMATE, 25, 3207-3218

Kumar, S., Hazra, A., \& Goswami, B.N. (2014). Role of interaction between dynamics, thermodynamics and cloud microphysics on summer monsoon precipitating clouds over the Myanmar Coast and the Western Ghats. CLIMATE DYNAMICS, 43, 911-924

LEPAGE, Y. (1971). A combination of Wilcoxon's and Ansari-Bradley's statistics. BIOMETRIKA, 58, 213-217

Li, C. (1996). The onset and interannual variability of the Asian summer monsoon in relation to land-sea thermal contrast. JOURNAL OF CLIMATE, 9, 358-375

Li, T., \& Ju, J. (2013). Comparison of climate features between the Southwest Summer Monsoon of the Bay of Bengal and the South China Sea Summer Monsoon. Chinese Journal of Geophysics- Chinese Edition, 56, 27-37

Li, X., Ting, M., Li, C., \& Henderson, N. (2014). Mechanisms of Asian Summer Monsoon Changes in Response to Anthropogenic Forcing in CMIP5 Models*. JOURNAL OF CLIMATE, 28

Liu, Y., Huang, G., \& Huang, R. (2011). Inter-decadal variability of summer rainfall in Eastern China detected by the Lepage test. THEORETICAL AND APPLIED CLIMATOLOGY, 106, 481-488

Lu, D., Yang, Y., \& Fu, Y. (2016). Interannual variability of summer monsoon convective and stratiform precipitations in East Asia during 1998-2013. INTERNATIONAL JOURNAL OF CLIMATOLOGY, 36, n/a-n/a

Lwin, T. (2000). The Prevailing Synoptic Situations in Myanmar. In. Yangon: Department of Meteorology and Hydrology

Ma, S., \& Zhou, T. (2016). Robust Strengthening and Westward Shift of the Tropical Pacific Walker Circulation during 1979 - 2012: A Comparison of 7 Sets of Reanalysis Data and 26 CMIP5 Models. JOURNAL OF CLIMATE, 29, 3097-3118

Matsuno, T. (1966). Quasi-Geostrophic Motions in the Equatorial Area. Journal of the Meteorological Society of Japan. Ser. II, 44, 25-43

Misra, V., \& DiNapoli, S. (2014). The variability of the Southeast Asian summer monsoon. INTERNATIONAL JOURNAL OF CLIMATOLOGY, 34

Paltridge, G., Arking, A., \& Pook, M. (2009). Trends in middle- and upper-level tropospheric humidity from NCEP reanalysis data. THEORETICAL AND APPLIED CLIMATOLOGY, 98, 351-359 
Pang-chi, \& Hsu (2011). Trends in global monsoon area and precipitation over the past 30 years. GEOPHYSICAL RESEARCH LETTERS

Parthasarathy, B., Munot, A.A., \& Kothawale, D.R. (1994). All-India monthly and seasonal rainfall series: 1871 - 1993. Theor.appl.climatol, 49, 217-224

Romatschke, U., \& Houze, R.A. (2011). Characteristics of Precipitating Convective Systems in the South Asian Monsoon. JOURNAL OF HYDROMETEOROLOGY, 12, 3-26

SABEERALI, C.T., RAO, S.A., AJAYAMOHAN, R.S., \& MURTUGUDDE, R. (2012). On the relationship between Indian summer monsoon withdrawal and Indo-Pacific SST anomalies before and after 1976/1977 climate shift. CLIMATE DYNAMICS, 39, 841-859

Seager, R., Liu, H., Henderson, N., Simpson, I., Kelley, C.P., Shaw, T.A., Kushnir, Y., \& Ting, M. (2014). Causes of increasing aridification of the Mediterranean region in response to rising greenhouse gases (Invited). JOURNAL OF CLIMATE, 27, 4655-4676

Seager, R., Naik, N., \& Vecchi, G.A. (2010). Thermodynamic and dynamic mechanisms for large-scale changes in the hydrological cycle in response to global warming. JOURNAL OF CLIMATE, 23, 4651-4668

Seager, R., \& Henderson, N. (2013). Diagnostic Computation of Moisture Budgets in the ERA-Interim Reanalysis with Reference to Analysis of CMIP-Archived Atmospheric Model Data*. JOURNAL OF CLIMATE, 26, 7876-7901

Sein, Z.M.M., \& Zhi, X. (2016). Interannual variability of summer monsoon rainfall over Myanmar. Arabian Journal of Geosciences, 9, 469

Sen Roy, S., \& Sen Roy, N. (2011). Influence of Pacific decadal oscillation and El Niño Southern oscillation on the summer monsoon precipitation in Myanmar. INTERNATIONAL JOURNAL OF CLIMATOLOGY, 31, 14-21

Shahi, N.K., Rai, S., Sahai, A.K., \& Abhilash, S. (2018). Intra-seasonal variability of the South Asian monsoon and its relationship with the Indo-Pacific sea-surface temperature in the NCEP CFSv2. INTERNATIONAL JOURNAL OF CLIMATOLOGY, 38, e28-e47

Shige, S., Nakano, Y., \& Yamamoto, M.K. (2017). Role of Orography, Diurnal Cycle, and Intraseasonal Oscillation in Summer Monsoon Rainfall over the Western Ghats and Myanmar Coast. JOURNAL OF CLIMATE, 30, 9365-9381

Shrivastava, S., Kar, S.C., \& Sharma, A.R. (2017). Inter-annual variability of summer monsoon rainfall over Myanmar. INTERNATIONAL JOURNAL OF CLIMATOLOGY, 37, 802-820

Takahashi, H.G., \& Yasunari, T. (2006). A Climatological Monsoon Break in Rainfall over Indochina -A Singularity in the Seasonal March of the Asian Summer Monsoon. JOURNAL OF CLIMATE, 19, 1545-1556

Turner, A.G., \& Annamalai, H. (2012). Climate change and the South Asian summer monsoon. Nature Climate Change, 2, 587-595

Ueda, H. (2009). Role of Warming over the Tibetan Plateau in Early Onset of the Summer Monsoon over the Bay of Bengal and the South China Sea. JOURNAL OF THE METEOROLOGICAL SOCIETY OF JAPAN, 76, 1-12

Walker, J.M., \& Bordoni, S. (2016). Onset and withdrawal of the large-scale South Asian monsoon: A dynamical definition using change point detection. GEOPHYSICAL RESEARCH LETTERS, 43, 11, $811-815,822$

Wang, B. (2002). Rainy Season of the Asian - Pacific Summer Monsoon*. JOURNAL OF CLIMATE, $15,386-398$ 
Wang, B., Liu, J., Kim, H.J., Webster, P.J., \& Yim, S.Y. (2012). Recent change of the global monsoon precipitation (1979-2008). CLIMATE DYNAMICS, 39, 1123-1135

Wang, S., Davies, R.E., Huang, W., \& Gillies, R.R. (2011). Pakistan's two-stage monsoon and links with the recent climate change. Journal of Geophysical Research: Atmospheres, 116

Wang, S.Y., Buckley, B.M., Yoon, J.H., \& Fosu, B. (2013). Intensification of premonsoon tropical cyclones in the Bay of Bengal and its impacts on Myanmar. JOURNAL OF GEOPHYSICAL RESEARCH-ATMOSPHERES, 118, 4373-4384

Watanabe, T., \& Yamazaki, K. (2014). Decadal-Scale Variation of South Asian Summer Monsoon Onset and Its Relationship with the Pacific Decadal Oscillation. JOURNAL OF CLIMATE, 27, 5163-5173

Xiang, B., \& Wang, B. (2013). Mechanisms for the Advanced Asian Summer Monsoon Onset since the Mid-to-Late 1990s*. JOURNAL OF CLIMATE, 26, 1993-2009

Xiao, D., \& Li, J. (2007). Spatial and temporal characteristics of the decadal abrupt changes of global atmosphere-ocean system in the 1970s. Journal of Geophysical Research: Atmospheres, 112

Yatagai, A., Kamiguchi, K., Arakawa, O., Hamada, A., \& Kitoh, A. (2012). APHRODITE: Constructing a Long-Term Daily Gridded Precipitation Dataset for Asia Based on a Dense Network of Rain Gauges. Bull.amer.meteor.soc, 93, 1401-1415 


\section{Figures}

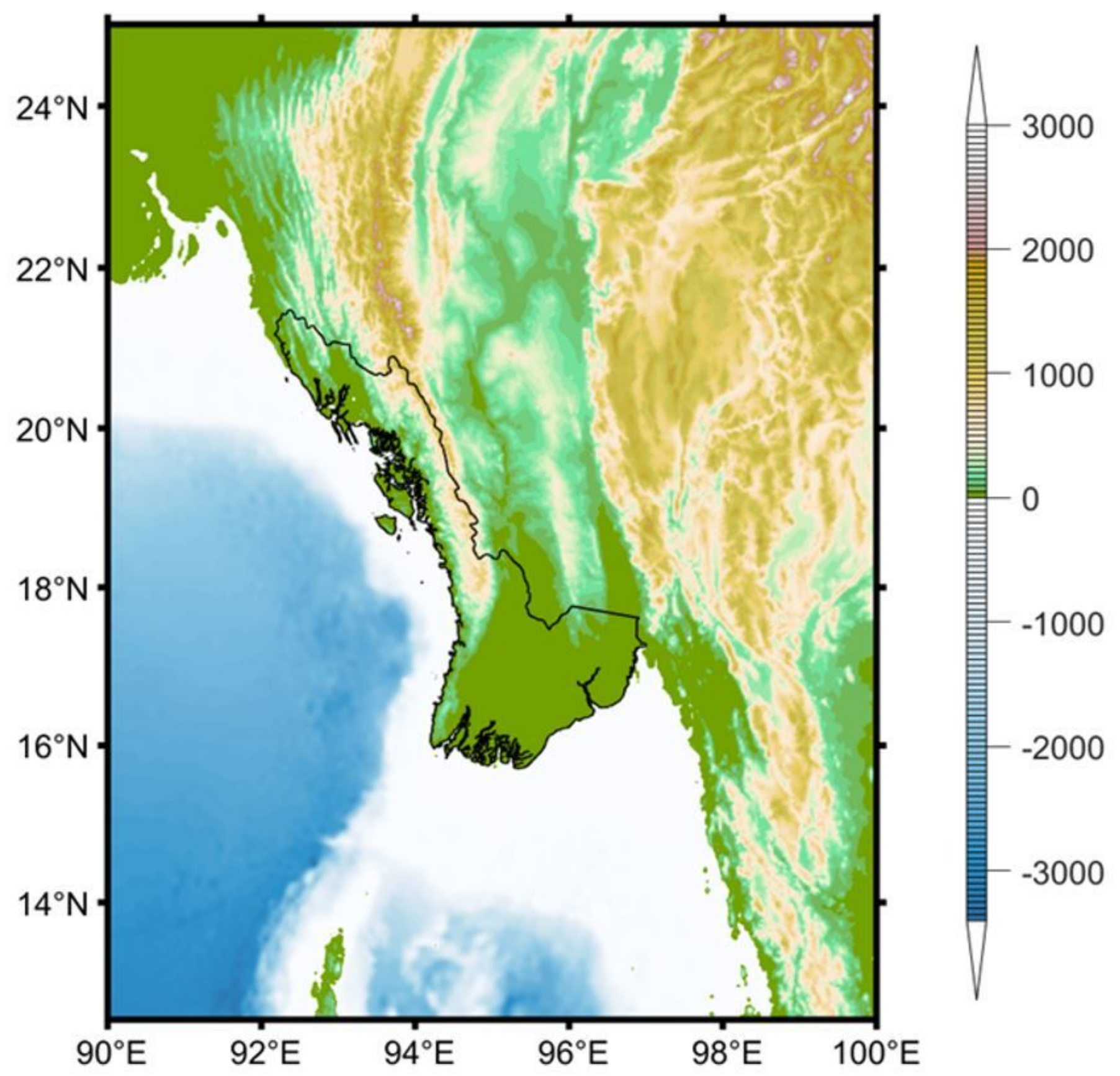

Figure 1

The topography of Myanmar Coast. Note: The designations employed and the presentation of the material on this map do not imply the expression of any opinion whatsoever on the part of Research Square concerning the legal status of any country, territory, city or area or of its authorities, or concerning the delimitation of its frontiers or boundaries. This map has been provided by the authors. 


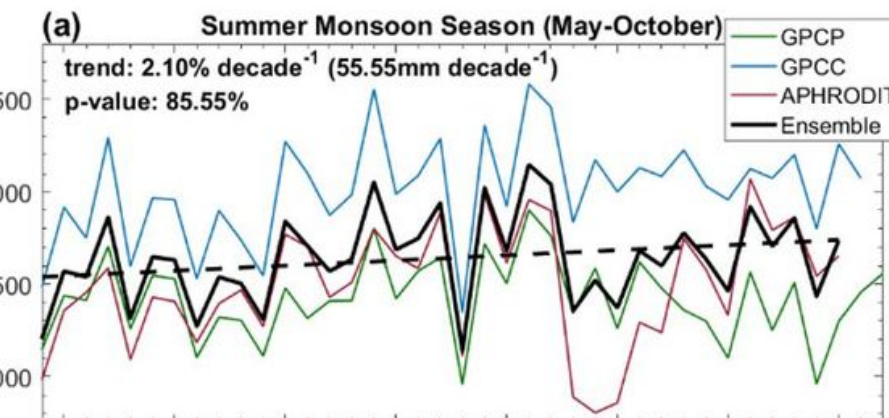

(c)

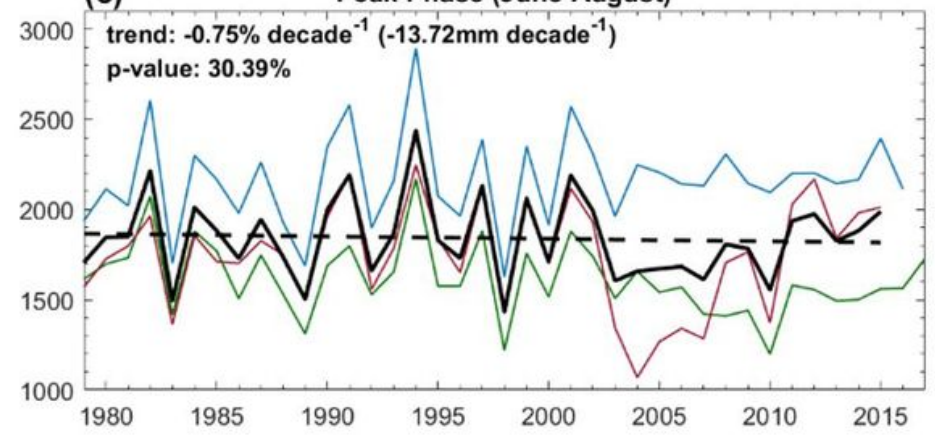

(b) Onset Phase (May)
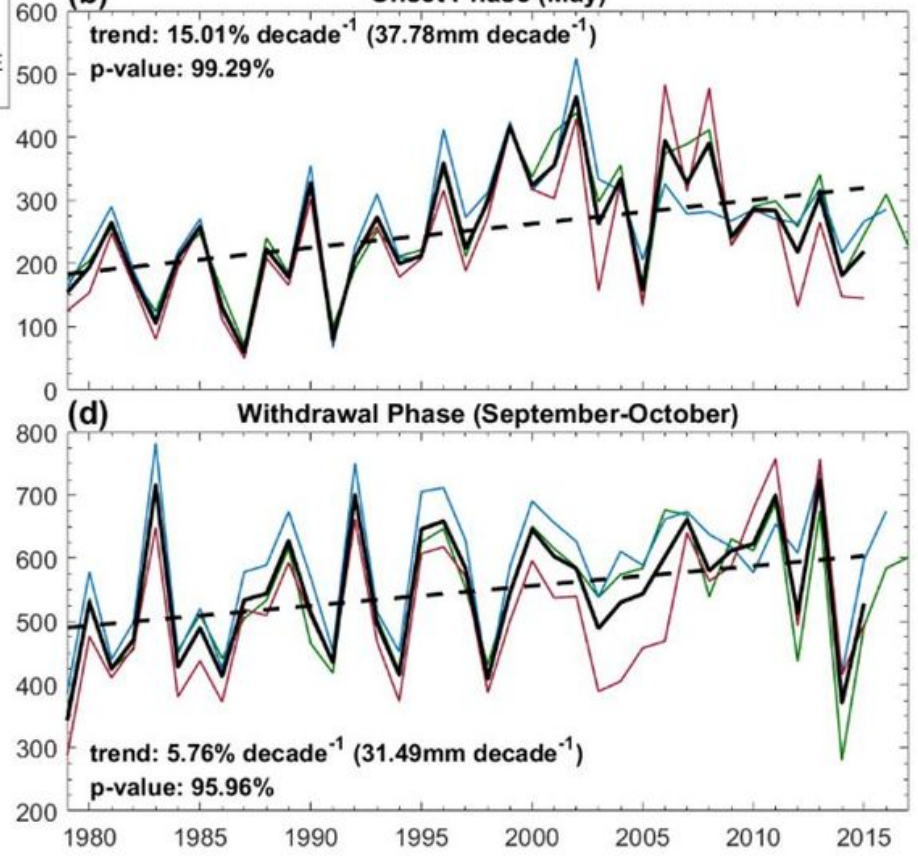

Figure 2

Time series of accumulated precipitation ( $\mathrm{mm}$ ) during (a) the whole monsoon season, (b-d) the onset, peak, and withdrawal phase of the monsoon season averaged over MC during 1979-2015 from all three precipitation datasets (thin lines), and their ensemble means (thick lines). Dashed black lines indicate the linear fit of precipitation time series, and the trends (\% decade- 1 or mm decade- 1 ) and confidence levels from the Mann-Kendall test are given. 
a

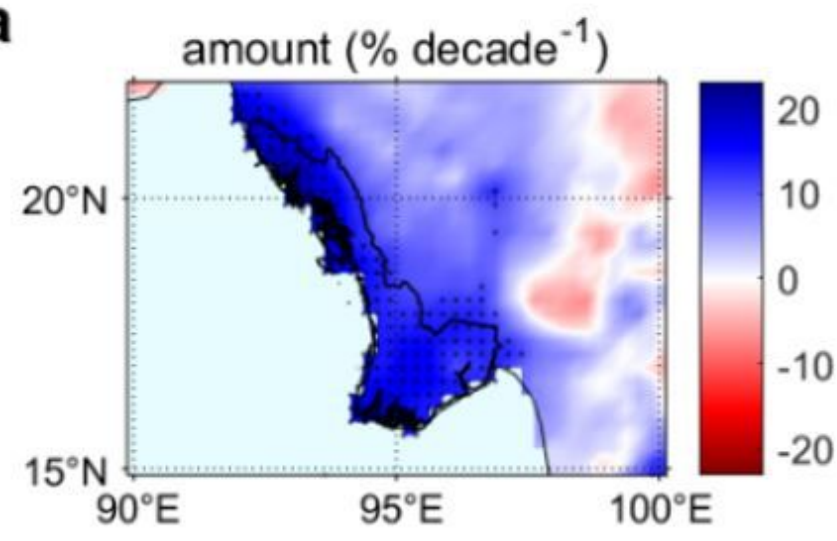

C

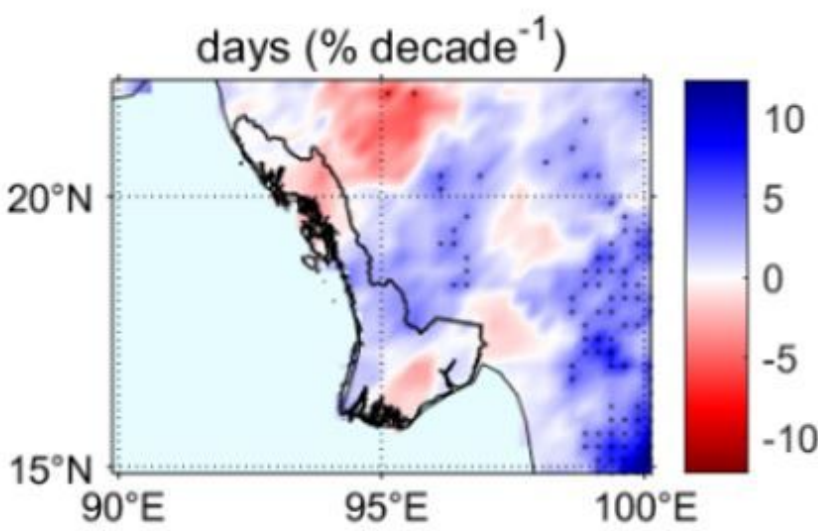

e

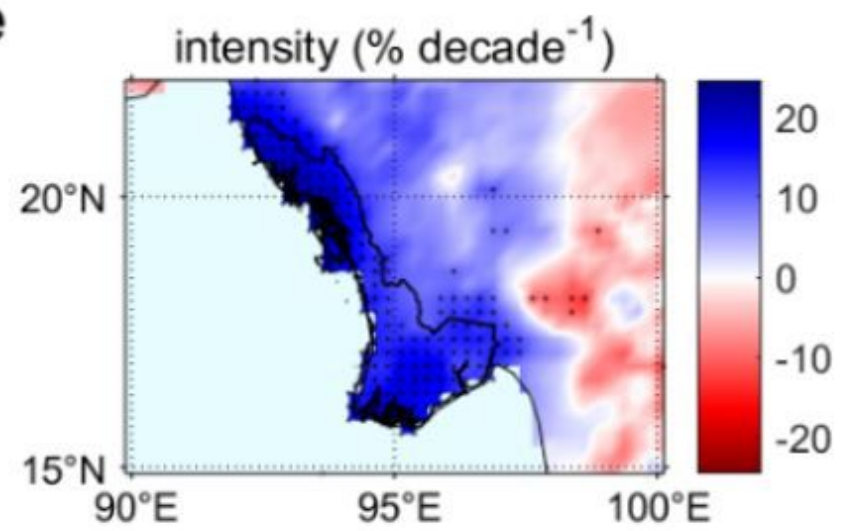

b

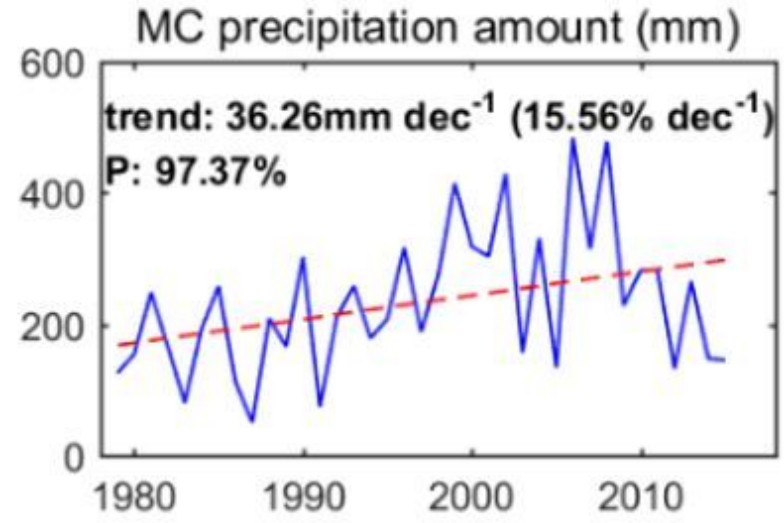

d

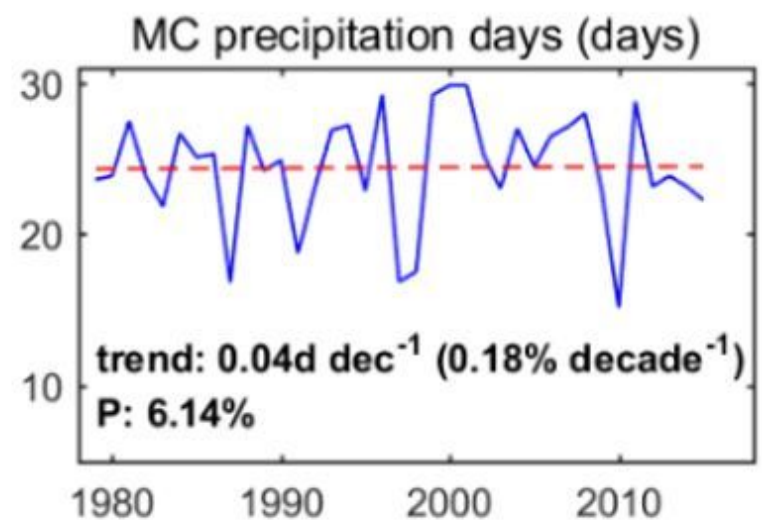

$\mathbf{f}$

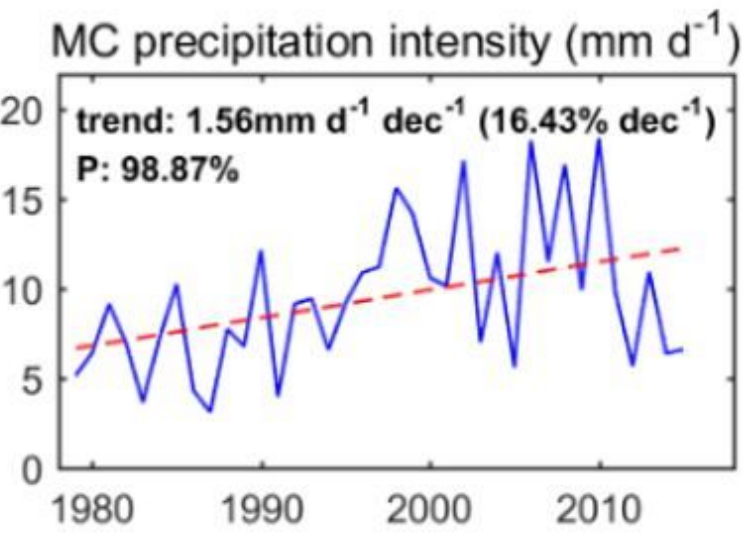

\section{Figure 3}

Linear trends in precipitation (a) amount, (c) days, and (e) intensity during MOP for the period 1979-2015 from APHRODITE (\% decade-1 relative to the climatology). Time series of MOP precipitation (b) amount (mm), (d) days (days), and (f) intensity (mm day-1) averaged over MC. Dashed red lines are linear fits of the time series. Note: The designations employed and the presentation of the material on this map do not imply the expression of any opinion whatsoever on the part of Research Square concerning the legal status of any country, territory, city or area or of its authorities, or concerning the delimitation of its frontiers or boundaries. This map has been provided by the authors. 
(a) $\operatorname{prcp}$ (GPCP)

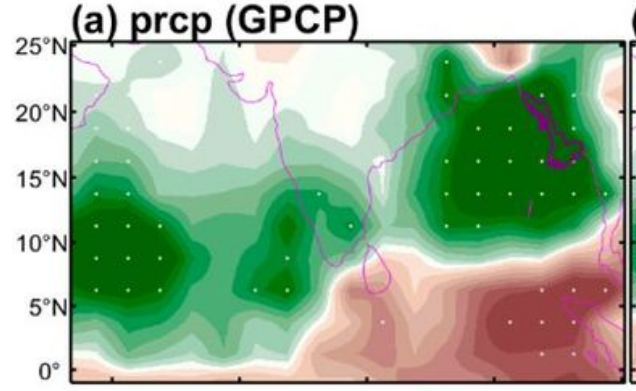

(d) thermodynamic

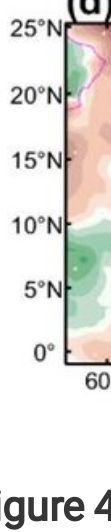

Linear trends in ( $a$ and $b$ ) precipitation from GPCP and ERA-interim, respectively, (c) the moisture

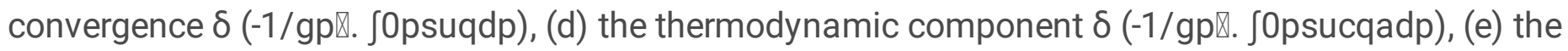

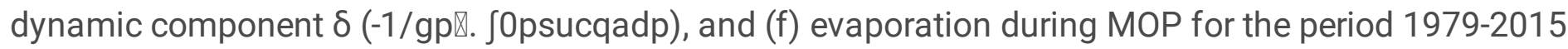
(shading, mm day-1 decade-1). Vectors in Fig. $4 \mathrm{e}$ are linear trends in 850 -hPa horizontal winds ( $\mathrm{m} \mathrm{s}-1$

decade-1). White dots indicate the $95 \%$ confidence level.

(c) moisture convergence

(b) $\operatorname{prcp}$ (ERAIM)

(e) dynamic

wind 850 (f) evaporation

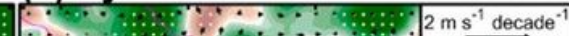

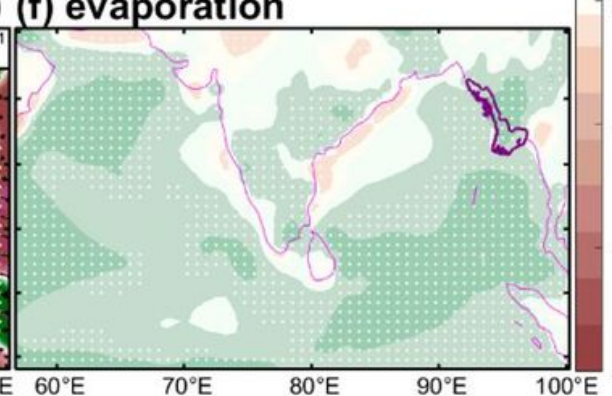

- 0

\section{Figure 4}




\section{Trend of 200-500 hPa thickness \& 200-hPa wind}

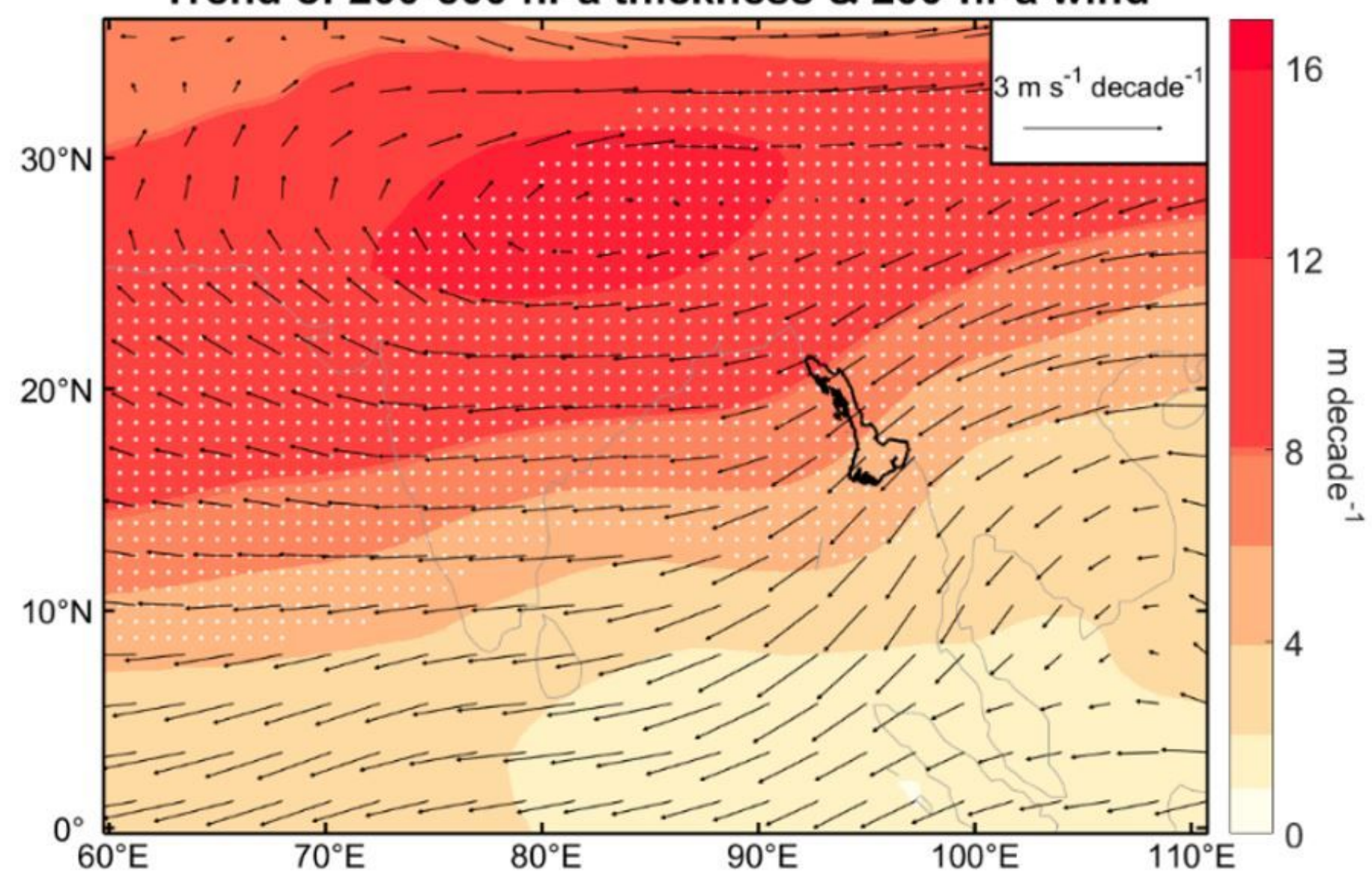

Figure 5

Linear trends of atmosphere thickness between $500 \mathrm{hPa}$ and $200 \mathrm{hPa}$ (shading, $\mathrm{m}$ decade-1) during MOP for the period 1979-2015. Vectors indicate linear trends of 200-hPa horizontal winds (m s-1 decade-1) during MOP during 1979-2015. White dots denote the 95\% confidence level. 


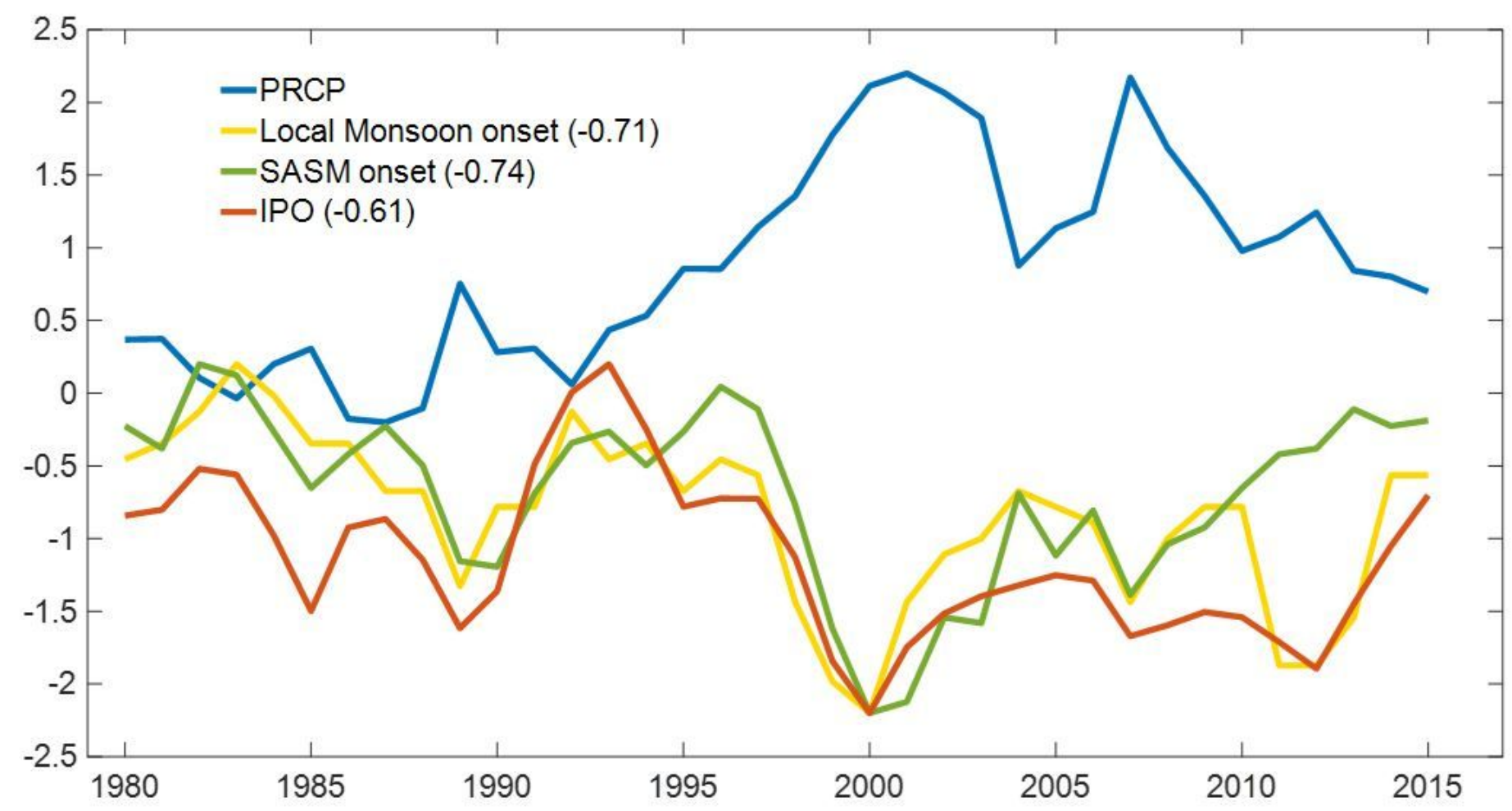

Figure 6

Normalized and 3 years moving average time series of MOP precipitation over MC (blue), the local onset date of the summer monsoon over MC (yellow), the SASM onset date (green), and the IPO Tripole Index for the onset phase (red). Correlation coefficients between precipitation and other indexes are given in parentheses. It should be noted that the correlation coefficients are estimated using the non-smoothed time series. 


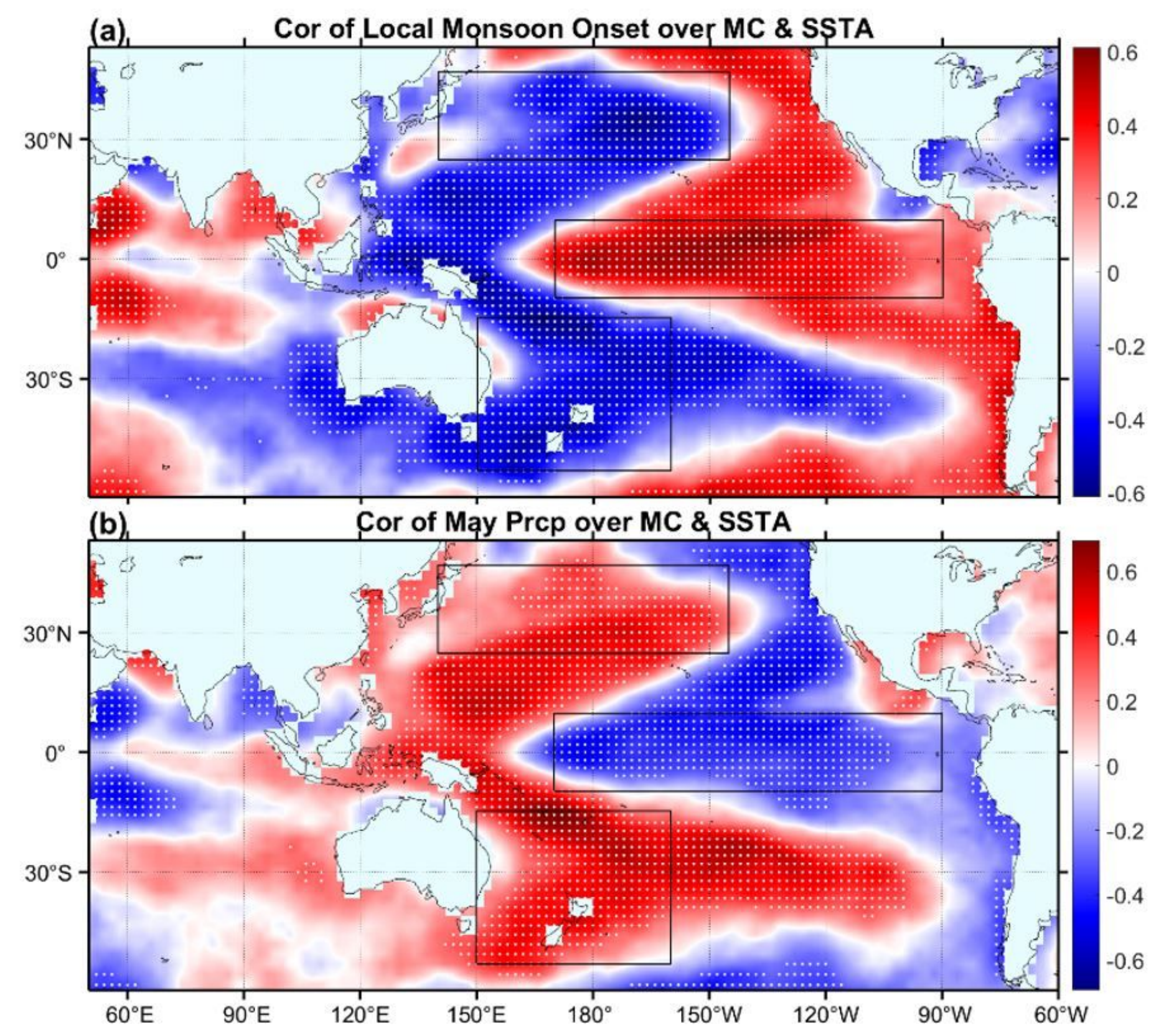

Figure 7

The correlation coefficients between SST anomalies during MOP with (a) the local onset date of the summer monsoon and (b) MOP precipitation over MC. White dots indicate the $95 \%$ confidence level. Black boxes denote the northwest $\left(25^{\circ}-45^{\circ} \mathrm{N}, 140^{\circ} \mathrm{E}-145^{\circ} \mathrm{W}\right)$, southwest $\left(50^{\circ}-15^{\circ} \mathrm{S}, 150^{\circ} \mathrm{E}-160^{\circ} \mathrm{W}\right)$, and central equatorial Pacific $\left(10^{\circ} \mathrm{S}-10^{\circ} \mathrm{N}, 170^{\circ} \mathrm{E}-90^{\circ} \mathrm{W}\right)$. Note: The designations employed and the presentation of the material on this map do not imply the expression of any opinion whatsoever on the part of Research Square concerning the legal status of any country, territory, city or area or of its authorities, or concerning the delimitation of its frontiers or boundaries. This map has been provided by the authors. 


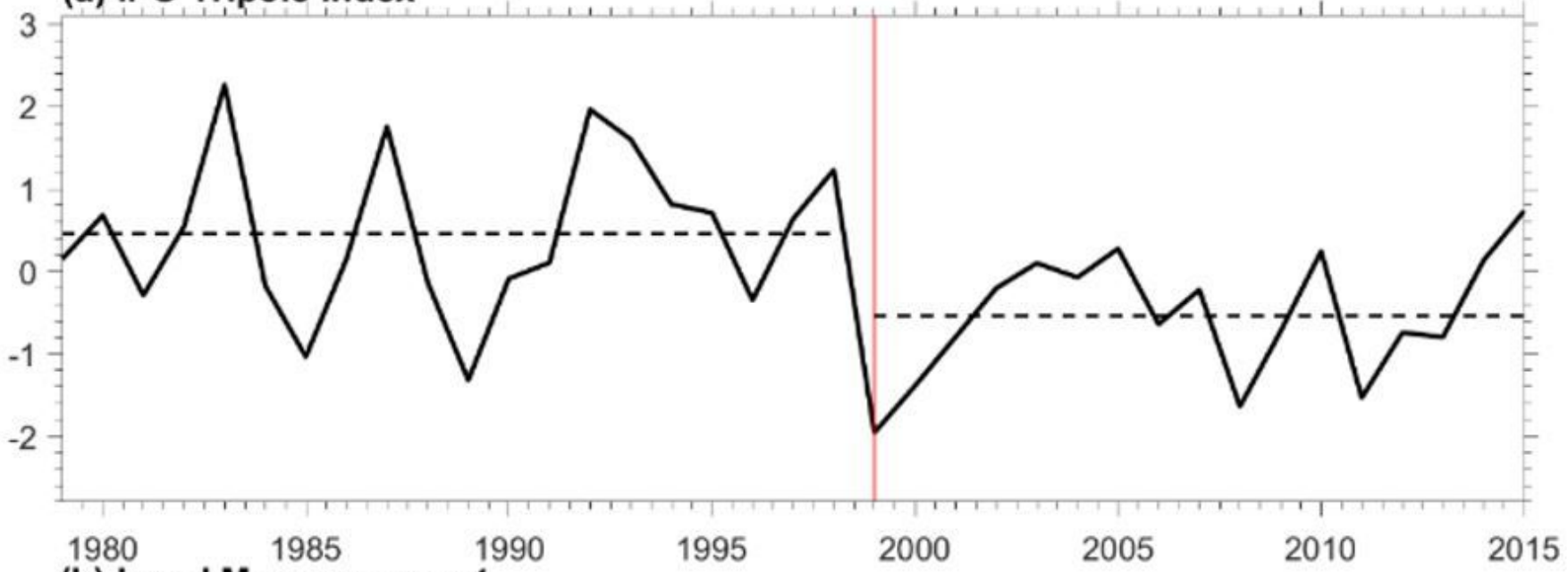

(b) Local Monsoon onset

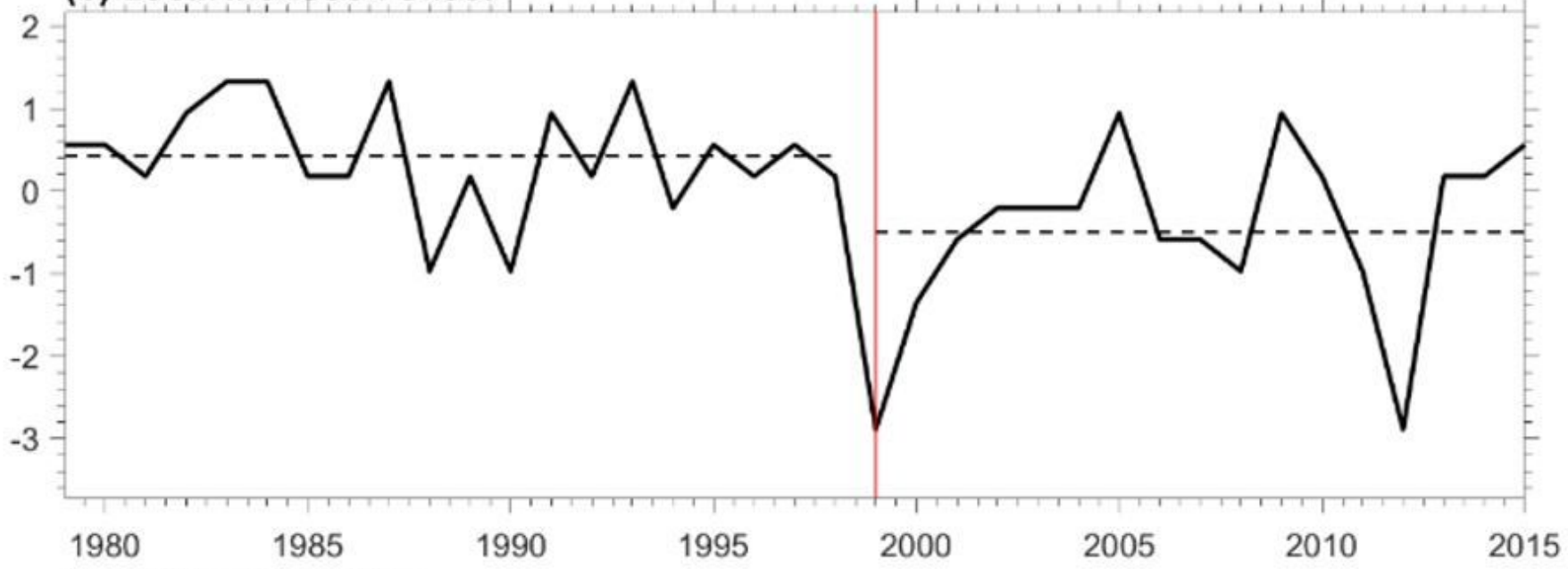

(c) May precipitation

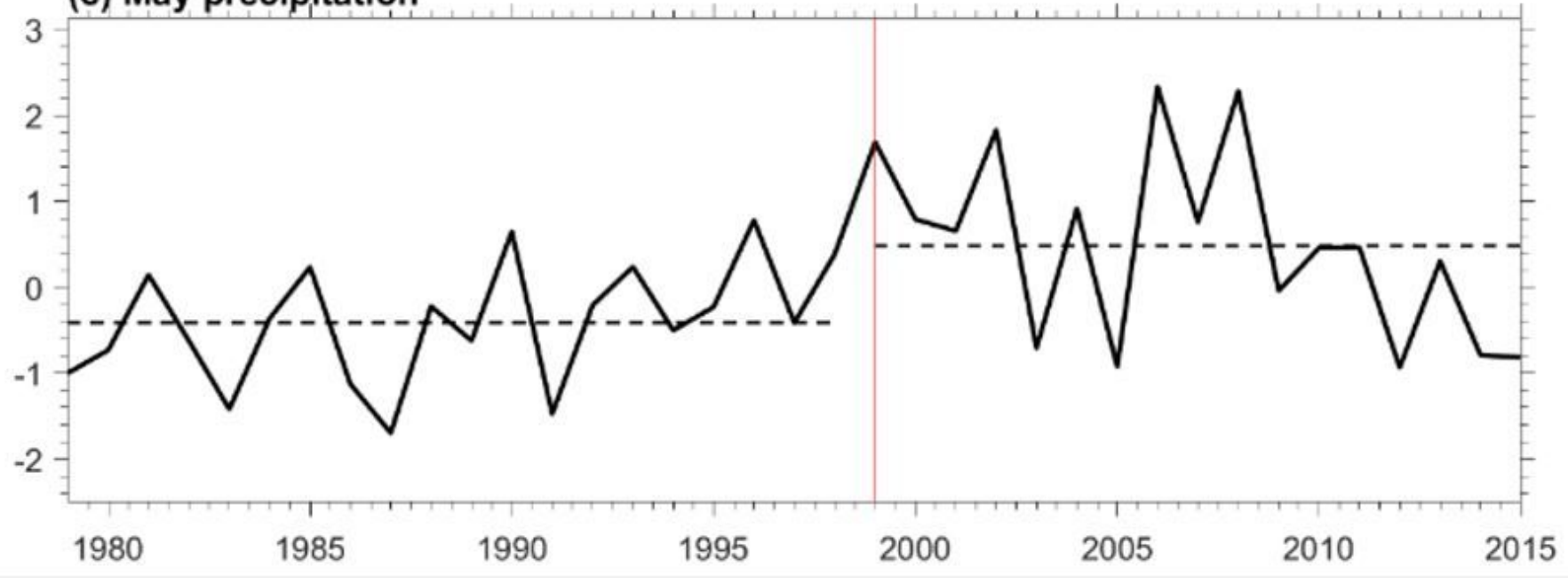

Figure 8

The normalized (a) IPO Tripole Index, (b) summer monsoon onset date over MC, and (c) MOP precipitation over MC for the period 1979-2015. The black dashed lines denote the mean value of these indices at each epoch separated by 1999. 

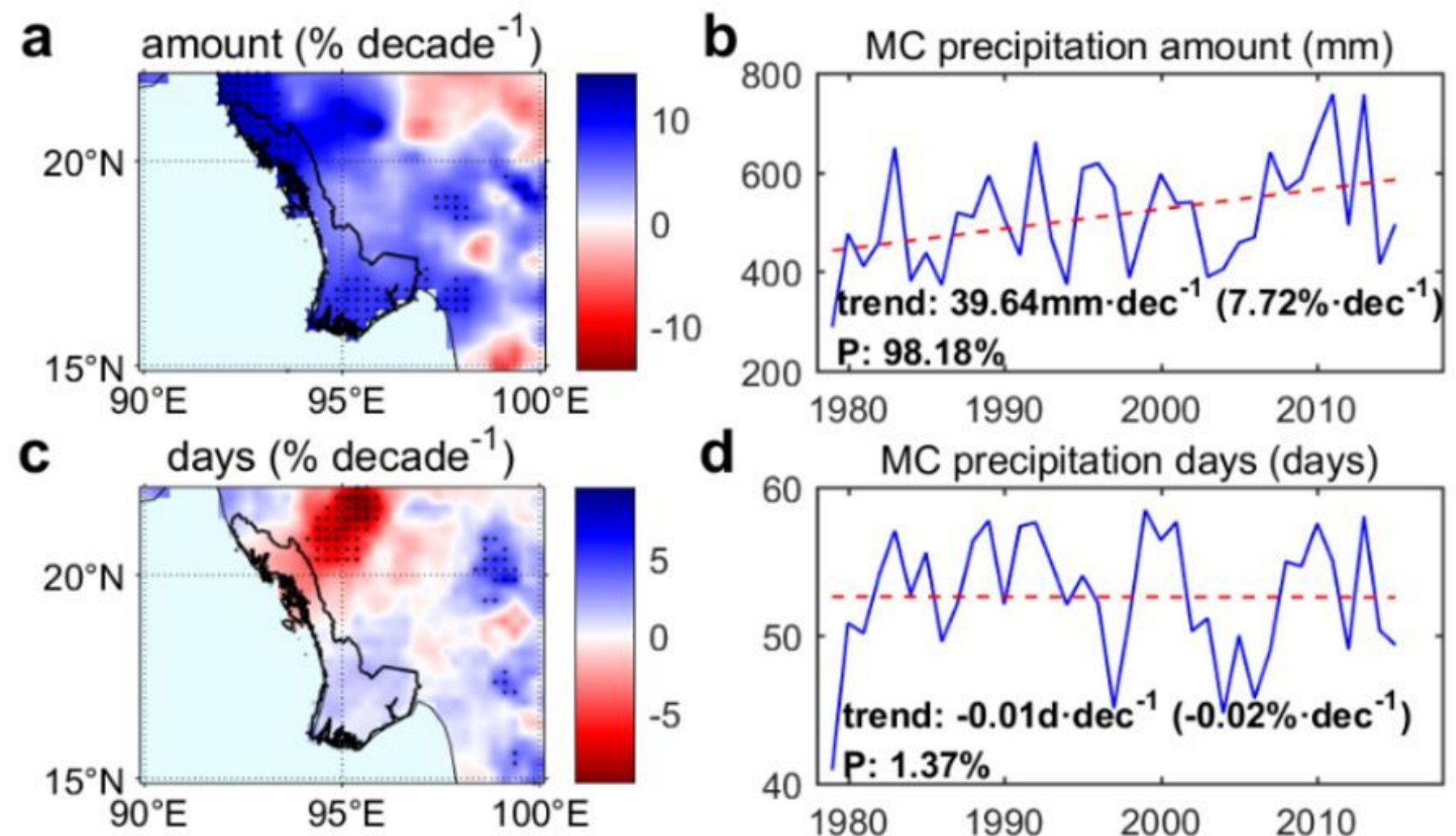

d

$1980 \quad 1990 \quad 2000 \quad 2010$

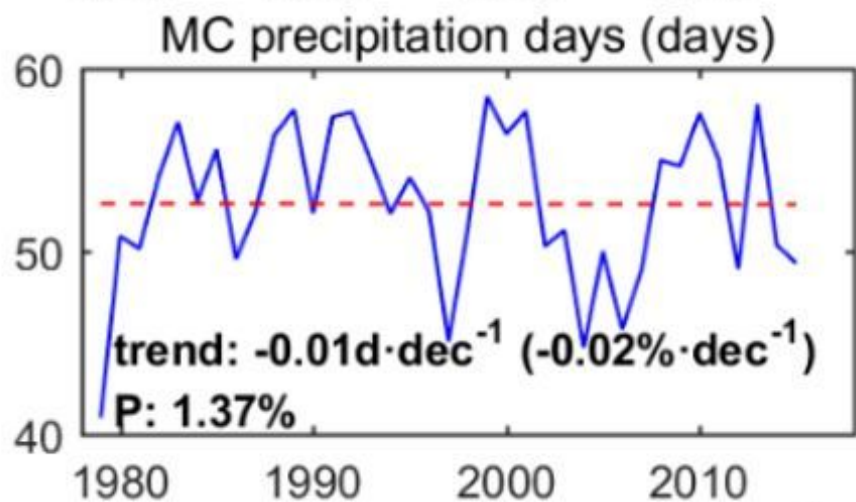

e intensity $\left(\%\right.$ decade $\left.^{-1}\right)$
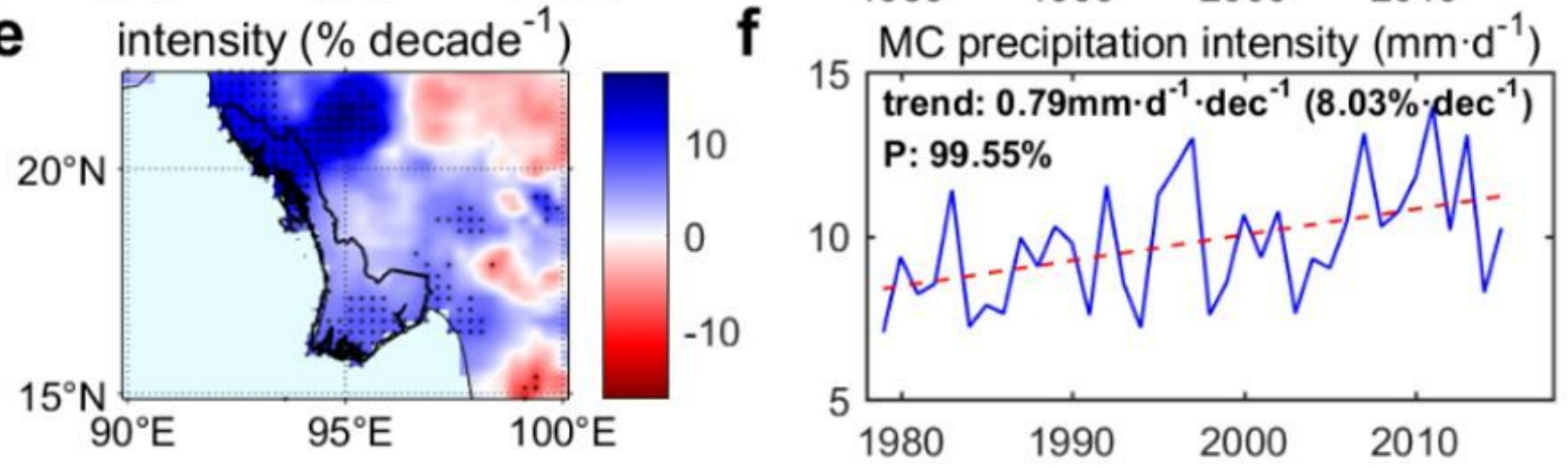

Figure 9

Linear trends in precipitation (a) amount, (c) days, and (e) intensity during MOP for the period 1979-2015 from APHRODITE (\% decade- 1 relative to the climatology). Time series of MOP precipitation (b) amount $(\mathrm{mm}),(\mathrm{d})$ days (days), and (f) intensity (mm day-1) averaged over MWP. Dashed red lines are linear fits of the time series. Note: The designations employed and the presentation of the material on this map do not imply the expression of any opinion whatsoever on the part of Research Square concerning the legal status of any country, territory, city or area or of its authorities, or concerning the delimitation of its frontiers or boundaries. This map has been provided by the authors. 
(a) $\operatorname{prcp}($ GPCP)

(b) $\operatorname{prcp}$ (ERAIM)

(c) moisture convergence

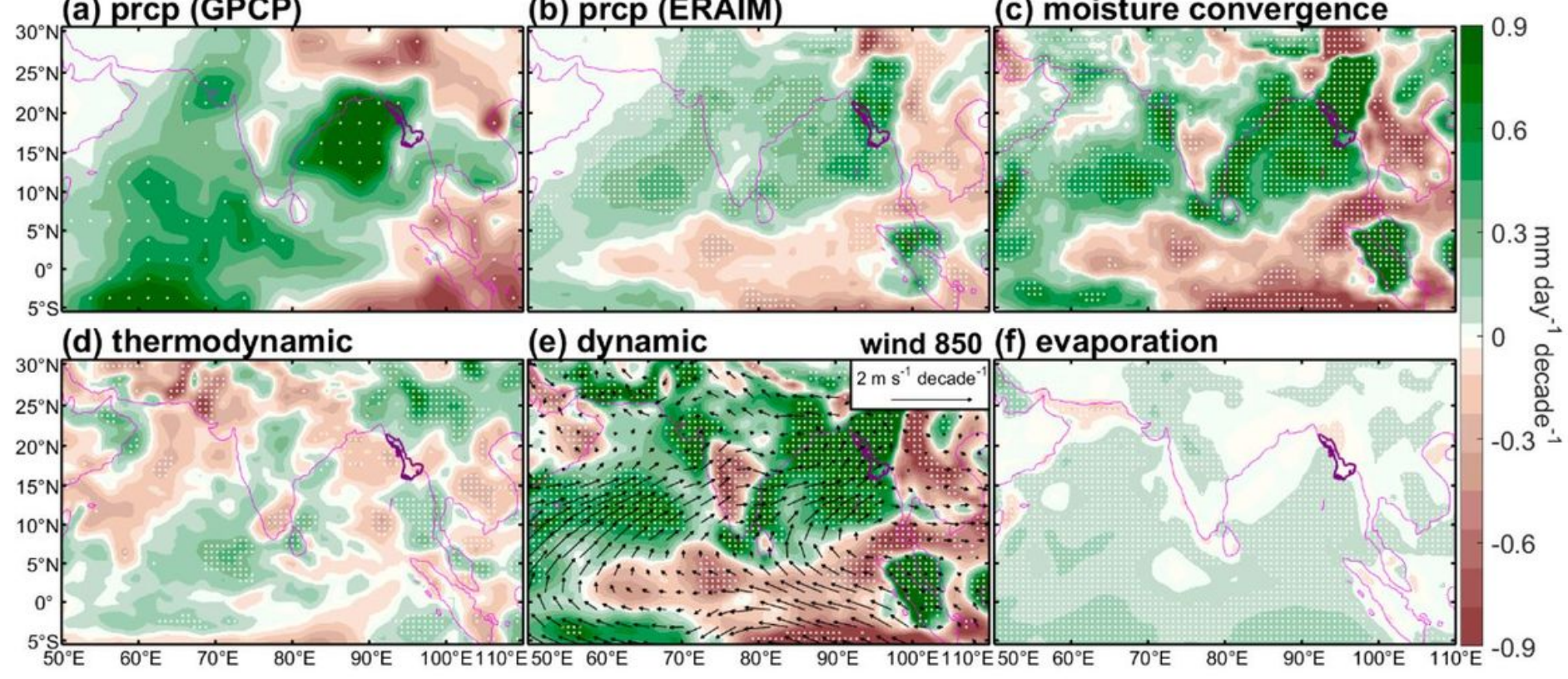

Figure 10

Linear trends in ( $a$ and $b$ ) precipitation from GPCP and ERA-interim, respectively, (c) the moisture

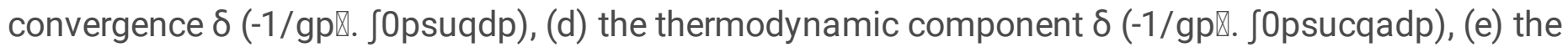
dynamic component $\delta$ (-1/gp》. SOpsucqadp), and (f) evaporation during MWP for the period 1979-2015 (shading, mm day-1 decade-1). Vectors in Fig. 4e are linear trends in 850-hPa horizontal winds ( $\mathrm{m} \mathrm{s}-1$ decade-1). White dots indicate the $95 \%$ confidence level. 


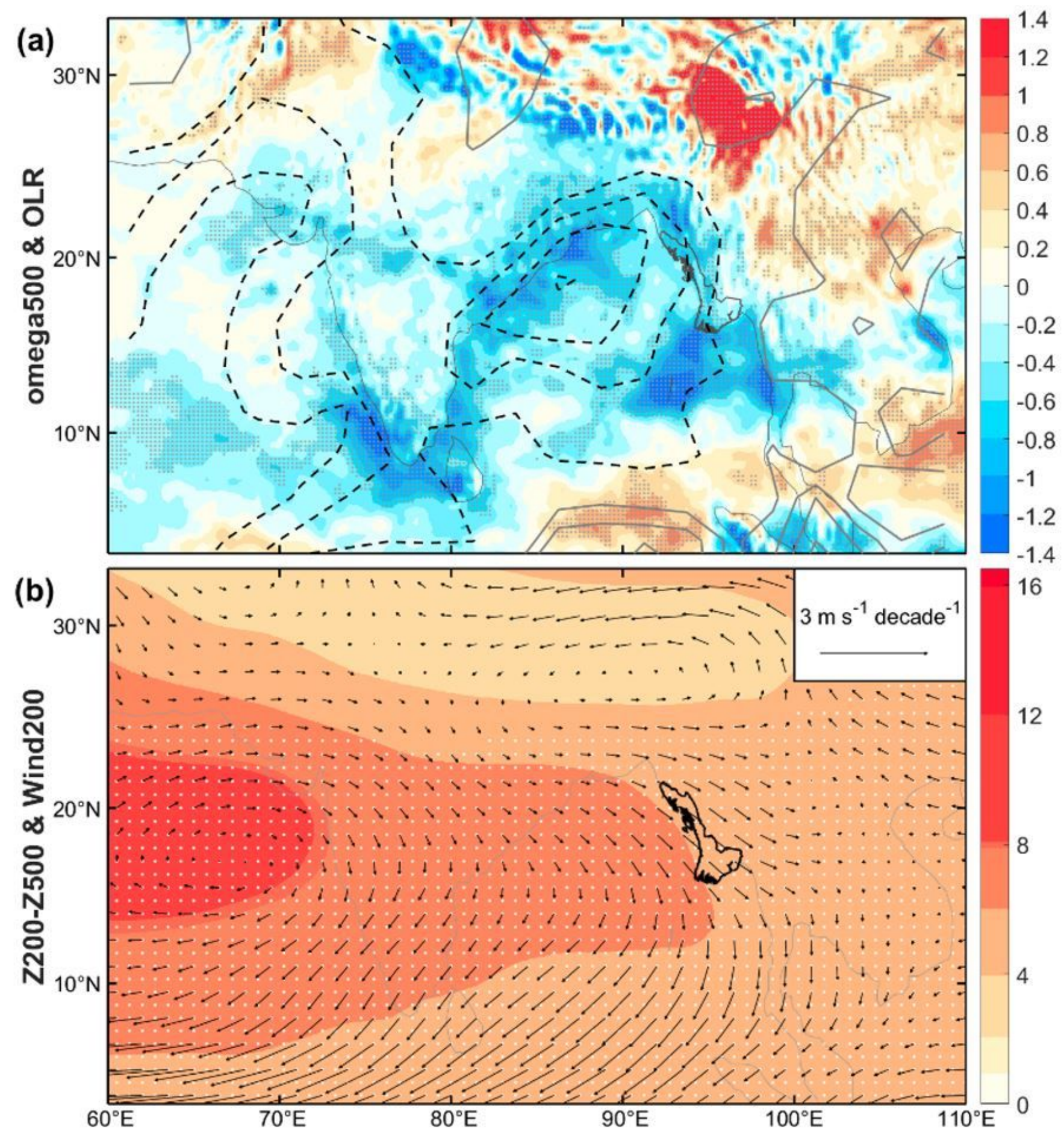

Figure 11

Linear trends of (a) 500-hPa vertical velocities (shading, 10-4 hPa s-1 decade-1) and OLR (contour, W m-2 decade-1), (b) thickness of $500 \mathrm{hPa}-200 \mathrm{hPa}$ (shading, m decade-1) and 200-hPa horizontal winds (vector, $\mathrm{m} \mathrm{s}-1$ decade-1) during MWP for the period 1979-2015. Dots denote the $95 \%$ confidence level. 


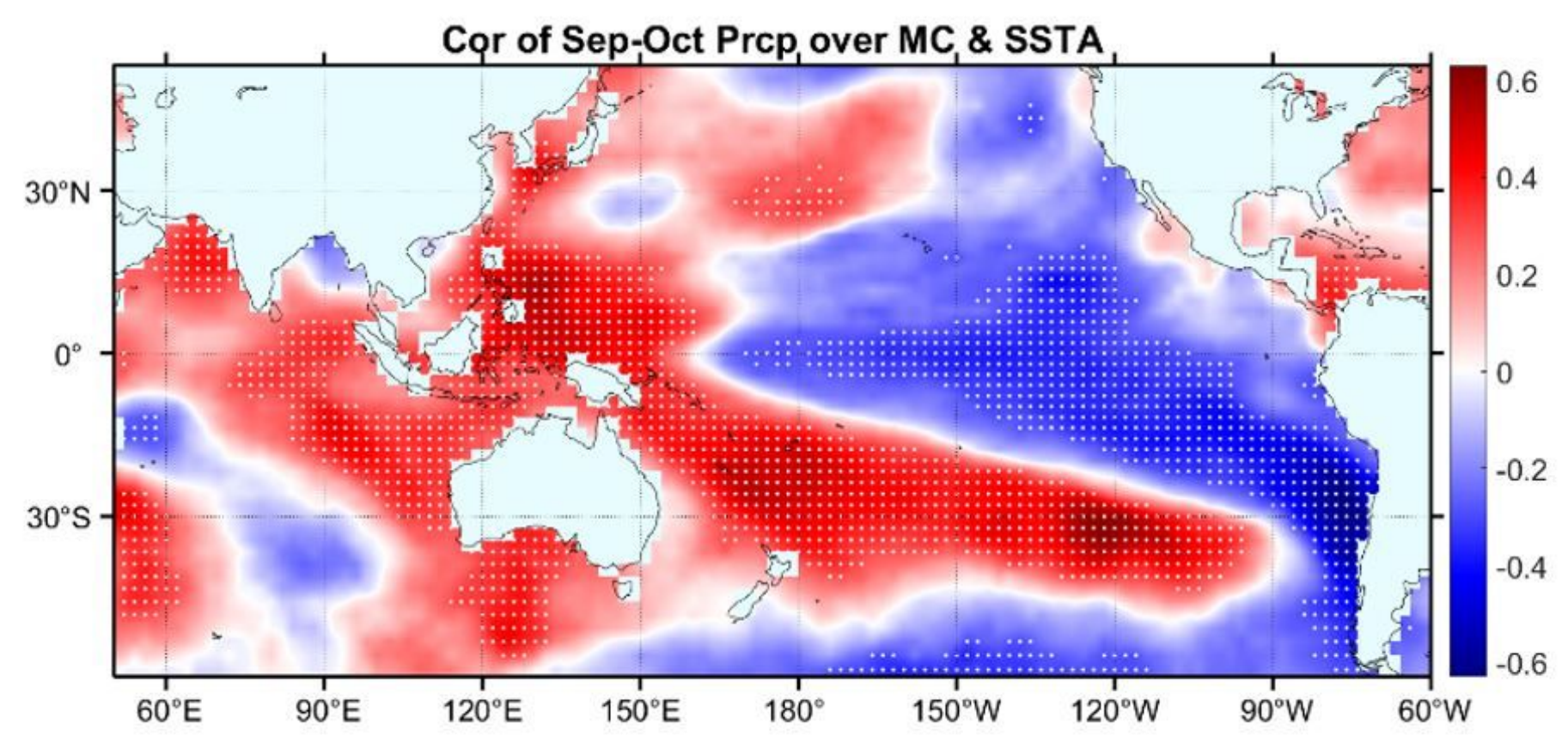

Figure 12

The correlation coefficients between SST anomalies during MOP with (a) the local onset date of the summer monsoon and (b) MOP precipitation over MC. White dots indicate the $95 \%$ confidence level. Note: The designations employed and the presentation of the material on this map do not imply the expression of any opinion whatsoever on the part of Research Square concerning the legal status of any country, territory, city or area or of its authorities, or concerning the delimitation of its frontiers or boundaries. This map has been provided by the authors. 